Article

\title{
Climatological Drought Forecasting Using Bias Corrected CMIP6 Climate Data: A Case Study for India
}

\author{
Alen Shrestha ${ }^{1}$, Md Mafuzur Rahaman ${ }^{2}$, Ajay Kalra ${ }^{1, *(1)}$, Rohit Jogineedi ${ }^{3}[$ \\ and Pankaj Maheshwari ${ }^{4}$ \\ 1 Department of Civil and Environmental Engineering, Southern Illinois University, 1230 Lincoln Drive, \\ Carbondale, IL 62901-6603, USA; alen.shrestha@siu.edu \\ 2 AECOM, 2380 McGee St Suite 200, Kansas City, MO 64108, USA; mafuzur.rahaman@aecom.com \\ 3 Department of Mechanical Engineering and Energy Processes, Southern Illinois University, 1230 Lincoln \\ Drive, Carbondale, IL 62901-6603, USA; rohit.jogineedi@siu.edu \\ 4 Louis Berger U.S.; Inc.; A WSP Company, 300 S. 4th Street, Suite 1200, Las Vegas, NV 89101, USA; \\ pankaj.maheshwari@wsp.com \\ * Correspondence: kalraa@siu.edu; Tel.: +1-(618)-453-7008
}

Received: 14 February 2020; Accepted: 20 April 2020; Published: 22 April 2020

\begin{abstract}
This study forecasts and assesses drought situations in various regions of India (the Araveli region, the Bundelkhand region, and the Kansabati river basin) based on seven simulated climates in the near future (2015-2044). The self-calibrating Palmer Drought Severity Index (scPDSI) was used based on its fairness in identifying drought conditions that account for the temperature as well. Gridded temperature and rainfall data of spatial resolution of $1 \mathrm{~km}$ were used to bias correct the multi-model ensemble mean of the Global Climatic Models from the Coupled Model Intercomparison Project Phase 6 (CMIP6) project. Equidistant quantile-based mapping was adopted to remove the bias in the rainfall and temperature data, which were corrected on a monthly scale. The outcome of the forecast suggests multiple severe-to-extreme drought events of appreciable durations, mostly after the 2030s, under most climate scenarios in all the three study areas. The severe-to-extreme drought duration was found to last at least 20 to 30 months in the near future in all three study areas. A high-resolution drought index was developed and proven to be a key to assessing the drought situation.
\end{abstract}

Keywords: drought index; bias correction; CMIP6; scPDSI; precipitation; temperature; forecast

\section{Introduction}

Drought is a complex phenomenon that slowly results in lasting impacts. The risks of drought are rising as a result of the depletion of the available surface and subsurface water resources. The social and economic well-being of a country is highly impacted by the effects of drought [1-3]. In developing countries, this impact is severe since their economies are based on agricultural products [4]. Also, the effects of climate change and extreme weather can worsen the drought and impede the overall socio-economic aspects [5]. Due to climate change, future projections of climate also show an increase in global drought events [6]. Various regional studies on drought suggest a rise in the trend, frequency, and intensity of droughts around the world [7-10]. On the regional scale, the effects of climate change are believed to be more prominent [11,12]. Therefore, the spatio-temporal pattern of future drought and the uncertainties associated with it should be understood to mitigate the effects of such calamities. An effective way to understand the drought characteristics in the future is by making 
the use of climatic projections from various global climate models (GCMs) under different greenhouse gas emission scenarios [13].

GCMs are essential tools for observing droughts in the wake of climate change. A vast majority of GCMs are created under the Climate Model Intercomparison Project (CMIP), which is a collective configuration designed to better the understanding of climate change. Climate Model Intercomparison Project Phase 3 and Climate Model Intercomparison Project Phase 5 (CMIP5) are the model ensembles developed based on Intergovernmental Panel on Climate Change (IPCC)'s fourth and fifth assessment report, respectively. These contain data output from numerous GCMs. These GCMs exhibit increased global aridity within the 21st century, mostly due to anthropogenic activities, leading to decreased precipitation in tropical and subtropical regions [14-16]. Future projections of Atmosphere-Ocean General Circulation Models show higher chances of increased wet extremes in regions where rainfall rises and increased severe dry extremes where rainfall decreases [17]. In order to quantify or possibly forecast the drought risks in the future using GCMs, various studies have been made $[18,19]$.

While GCMs are key to defining atmospheric as well as oceanic processes, the spatial scale in which the models operate is limited. The performance of the GCMs is known to be satisfactory at inter-continental and large regional scales, yet the ability to accurately characterize the climate at a finer spatial scale is underexplored and unsatisfactory. The coarse resolution of the GCMs restricts the studies and fails to provide the information at a regional scale for drought impact in present and future periods. To address this shortcoming of the GCMs, the downscaling of GCMs is required to obtain the local future climatic situations. Along with the limitations posed by the resolution of the climatic models, the biases contained in it impede the assessment of climate at a regional level [20,21]. Although the temperature and precipitation simulated by climate models at a large scale can be accurate [22], the biases can hamper the analysis on regional scales. To quantify and remove this bias, various techniques are applied in the raw climate model output, such as quantile mapping [23], correction of monthly means [24], and quantifying the delta change [25]. Out of all these methods, the most widely used method is quantile mapping, which matches statistical moments with due consideration to observations by adjusting the distribution of the output from the model.

The effects of droughts can be seen in any climatic zone, but extreme effects can be seen in tropical and sub-tropical regions like India [26]. An increase in the severity of climatological droughts is predicted in the future in various sub-regions of India, according to studies [27,28]. With greater influences of climate change and anthropogenic effects [29], drought is leading to problems in the agricultural sector [30]. With about $16 \%$ of the total geographic area of India being arid and about $37 \%$ of the area being semi-arid region [31], drought will likely affect the agricultural economy. The possibility of long-term and short-term drought in a developing country like India will have threatening impacts on household water supply, energy generation, and food stock. Such effects are seen in drought-prone Indian regions such as Rajasthan, Punjab, West Bengal, and Uttar Pradesh, which have been evident throughout the past century [32,33]. The risk of such problems might be further exacerbated in India due to droughts induced by low and variable rainfall during the monsoon season [34]. The Indian summer monsoon, which is a vigorous regional rainfall event spreading through June till September, shows spatio-temporal variability [35]. Moreover, the sensitivity of monsoon to anthropogenic activities [36] could add to the complexity, making the monsoon climate in India more unpredictable [37]. Climate models also suggest an increased intensity and frequency of extreme dry and wet episodes in India [38]. In addition, the changes in the spatial distribution of rainfall over India [39] may evolve into a near-catastrophic drought in the future. Likewise, the IPCC [40] has suggested an increased risk of drought events over the arid regions of India. Furthermore, an increase is projected in the temperature by about 1.5 to $3^{\circ} \mathrm{C}$ in India [41]. Therefore, the study of climatological drought in the future using the projected climate at relevant spatial and temporal scale is important for Indian regions.

Concerning the drought in India, most of the studies have centered on assessing the past drought and predicting the trends that lead to future drought [42-44]. Mallya et al. [43] detailed an 
increasing trend of drought in terms of severity and frequency in India. Naresh et al. [45] indicated the increase in the area coverage of moderate drought conditions in India in recent decades. However, to forecast future droughts, researchers used GCM-based future climate data. Ojha et al. [46] discussed the rise of drought events in different regions of India using monthly time series of GCMs based on precipitation-dependent drought indicator Standard Precipitation Index (SPI) at a coarse scale. Using bias-corrected and spatially disaggregated data, Mishra et al. [42] claimed an increase in the spatial extent and rise in occurrence of severe to extreme droughts in upcoming decades at a spatial scale of $0.25^{\circ}$. Studies concerning the Indian regions mostly used the precipitation-based drought indicator SPI under the future projected climate. While precipitation is considered as fundamental to analyze drought conditions, the role of temperature is also highly regarded when considering climate change [47]. Drought indicators such as the Standard Precipitation and Evapotranspiration Index [48] and scPDSI accounts for temperature in its formulation to incorporate the high water demand of the atmosphere following an increase in temperature. Likewise, studies concerning droughts in India have used several methods of bias correction of GCMs. These bias correction methods generally function by assuming the statistical link between the observed and the simulated values. The status of such a statistical relationship is used to predict the change in future data [23]. Therefore, the equidistant quantile-based mapping method (EDCDFm) formulated by Li et al. [49] is preferred because of its ability to account for changes in the future climate fields of GCMs.

The current study concentrates on the spatial distribution and severity of future drought conditions in three topographically and meteorologically distinct areas in India. The state of the art Climate Model Intercomparison Project Phase 6 (CMIP6)-based climate data will be used to forecast and assess the near future drought situation (2015-2044) at a fine resolution of $1 \mathrm{~km}$ using a robust drought indicator, scPDSI. The new set of climate projections under CMIP6 was established based on different socioeconomic assumptions. The new scenarios, defined as shared socio-economic pathways (SSP), are guided by a set of different land use and emissions constraints obtained under integrated assessment models [50]. The CMIP5 features representative concentration pathways (RCPs) that inspect various probable greenhouse gas emission levels in the future. These CMIP5 scenarios, namely, RCP2.6, RCP4.5, RCP6.0, and RCP8.5, are updated differently in CMIP6. These scenarios are known as SSP1-2.6, SSP2-4.5, SSP4-6.0, and SSP5-8.5. Various SSPs have been qualified to run climate models for CMIP6. Since the simulated climate data from a few GCMs and limited ensembles will not be sufficient enough to account for the uncertainties involved to assess the future processes, the multi-model ensemble (MME) mean will be used. This work will depict the severity of CMIP6 GCMs-induced drought on a regional scale, considering different environmental and socio-economic scenarios in the near future. Upon completion of this research work, the expected outcomes will be helpful in responding to the following questions.

(1) How will the emission, land use, and social changes affect the drought situation in the future?

(2) How will the simulated drought change in terms of severity, length, and spatial extent?

\section{Study Area}

The analysis was performed in three different study areas that vary topographically in terms of distinct aridity. The three study areas are from western, central, and eastern India. A brief overview of each of the study areas is presented. The three different study areas are the Araveli region (AV), the Bundelkhand region (BK), and Kansabati river basin (KSB).

\subsection{Study Area 1- the Araveli Region}

The AV is located in Rajasthan, India, which lies in the northwestern part of the country, as shown in Figure 1a. The region is dominated by the presence of a range of old mountains stretching from northeast to southwest. The mountains run approximately $700 \mathrm{~km}$, covering around $40,000 \mathrm{~km}^{2}$. The elevation ranges from 300-670 m above the mean sea level, while major peaks of Araveli Hills 
range from 700 to $1700 \mathrm{~m}$ above the mean sea level. The region experiences dry climate most of the year, outside of the monsoon/rainy season. June through September are the windiest, adding an erratic pattern to rainfall. The agricultural practices and vegetation are dependent upon monsoon. Irregular geomorphological and topographical conditions throughout the region lead to varying aquifer situations where water resource availability shifts from one place to the other. Monsoon crops, also known as the major crop, are cultivated in the months of June through September. October through March are the months spent sowing and harvesting these crops. The months from March through May are a major time for irrigation to cultivate summer crops. The mean annual rainfall for the study area is approximately $674 \mathrm{~mm}$.
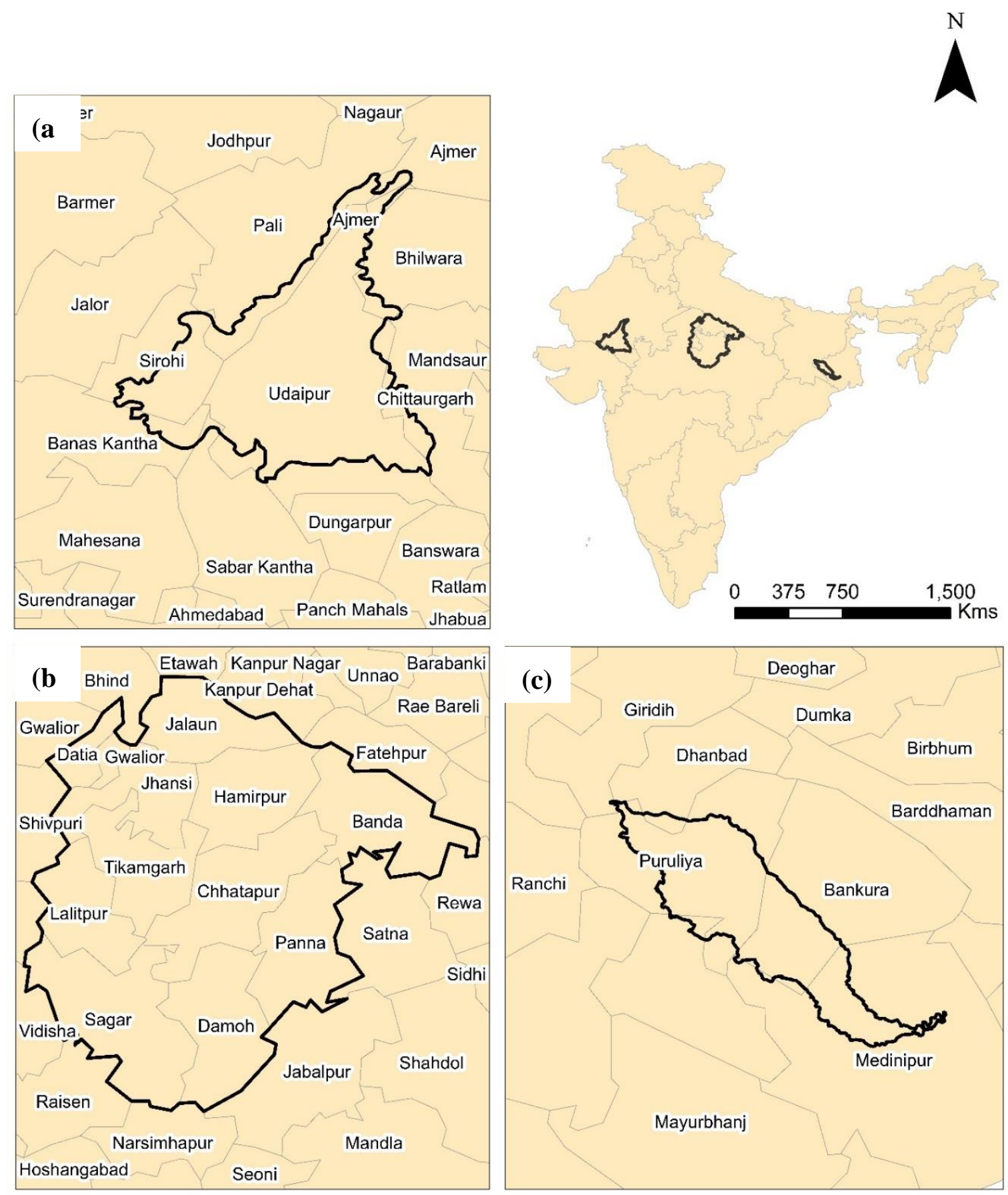

Figure 1. Study area map of each of the study area. (a) Araveli region (b) Bundelkhand region (c) Kansabati river basin. 


\subsection{Study Area 2-Bundelkhand Region}

The BK lies between two big states of India, namely, Uttar Pradesh and Madhya Pradesh, as shown in Figure $1 \mathrm{~b}$. The domain stretches between $78^{\circ} 11^{\prime} \mathrm{E}$ and $81^{\circ} 30^{\prime} \mathrm{E}$ longitude and $23^{\circ} 08^{\prime} \mathrm{N}$ and $26^{\circ} 30^{\prime} \mathrm{N}$ latitude. The geographical area of the study area is $71,619 \mathrm{~km}^{2}$. The elevation for this study area varies between 200 and $400 \mathrm{~m}$ above the mean sea level. A dry sub-humid climate with a rainy season from June to September is faced by this region. A population of around 15 million is dependent on rainfed agricultural practices. Major rivers flow through and around this region: Bhetwa, Tons, Pahuj, Sindh, and Chambal, being a few. The topography of the study area is governed by a rather uneven land filled with undulations and rugged terrain. Monsoon and summer seasons based on agricultural products such as wheat and soybeans are major products. Annual agricultural production is constituted by sugarcane, pulses, and cereals, being the majority of all. The mean annual rainfall varies from 800 to $1000 \mathrm{~mm}$.

\subsection{Study Area 3-Kansabati River Basin}

The KSB lies upstream from the Kansabati Dam. The study area is a portion of the river basin that falls to the extreme west of West Bengal, which is geographically situated between $72^{\circ} 16^{\prime} \mathrm{E}$ and $74^{\circ} 28^{\prime} \mathrm{E}$ longitude and $73^{\circ} 19 \mathrm{~N}$ and $74^{\circ} 16^{\prime} \mathrm{N}$ latitude, as shown in Figure 1c. The physical area of the region is $6404 \mathrm{~km}^{2}$. The elevation lies between 110 and $600 \mathrm{~m}$ above the mean sea level. During the very hot summer in May and June, the region experiences temperature up to $45^{\circ} \mathrm{C}$. Higher temperature leads to an increased rate of evaporation directly influencing the natural vegetation as well as agricultural practices in the region. The area is well equipped with an irrigation facility. The major crop products of the region are maize, wheat, paddy, pulses, vegetables, and so on. Due to the low water-retaining capacity of the lateritic soils along with the irregular rainfall, the basin is considered a drought-prone area. Huge exploitation of groundwater resources to favor increasing cultivation has led to an increase in water demands recently. The mean annual rainfall in the area is roughly $1268 \mathrm{~mm}$.

\section{Data and Methodology}

\subsection{Data}

CMIP6 historical observations (1950-2014) and future observations (2015-2044) of precipitation and maximum and minimum temperature for different SSPs were used. CMIP6 climate variables such as precipitation $(\mathrm{Pr})$, maximum temperature $\left(\mathrm{Tas}_{\max }\right)$ and minimum temperature ( $\left.\mathrm{Tas}_{\min }\right)$, wind speed $(\mathrm{w})$, cloud cover (ccl), were obtained for each of the available models and scenarios at monthly time-scales. Each of the SSP is established based on a certain level of radiative forcings related to emissions, land-use scenarios, and societal concerns. CMIP6 multi-model climate projections are the outcome of the Scenario Model Intercomparison Project (ScenarioMIP); the projections are based on alternative scenarios pertinent to societal concerns regarding climate change relief, impacts, and assimilation. A list of all the CMIP6 models used in this work is presented in Table 1.

Table 1. CMIP6 models employed with their respective spatial resolution.

\begin{tabular}{ccc}
\hline Model & Modeling Institution & Spatial Resolution (km) \\
\hline BCC-ESM1 & Beijing Climate Center Earth System Model & $250 \times 250$ \\
\hline CanESM5 & Canadian Centre for Climate Modelling and Analysis & $500 \times 500$ \\
\hline CNRM-CM6-1 & National Centre for Meteorological Research & $250 \times 250$ \\
\hline CNRM-ESM2-1 & Centre National de Recherches Meteorologiques & $250 \times 250$ \\
\hline GISS-E2-1-G & Goddard Institute for Space Studies & $250 \times 250$ \\
\hline GISS-E2-1-H & Goddard Institute for Space Studies & $250 \times 250$ \\
\hline MIROC6 & Model for Interdisciplinary Research on Climate & $500 \times 500$ \\
\hline
\end{tabular}


For the current study, three scenarios (SSP5-8.5, SSP2-4.5, and SSP1-2.6) have been considered and are detailed in the supporting literature of $\mathrm{O}^{\prime} \mathrm{Neill}$ et al. [50].

Conventionally, the analysis of future droughts mostly uses limited climate models to assess possible impacts. Since the outcomes of GCMs vary widely within the scenarios, the application of the MME mean to account for the uncertainty in ensemble outputs has become a usual practice in climate science research. Conditions for the selection of models in this work were based primarily on the availability of future projections. This study considers all the available models within CMIP6, which is still in its incipient stage. Figures $2-4$ show the historical and the projected period and the respective maximum and minimum values among all GCMs to exhibit the range of climate variables. The computed MME mean represents the precipitation, and maximum and minimum temperatures well within the variation range in every study area, as shown in Figures $2-4$. The MME mean values indicate proper representation of the extremes of both the climate variables with temperature values in the increasing order during the projected period, whilst a very slight increase in the precipitation for the same period.

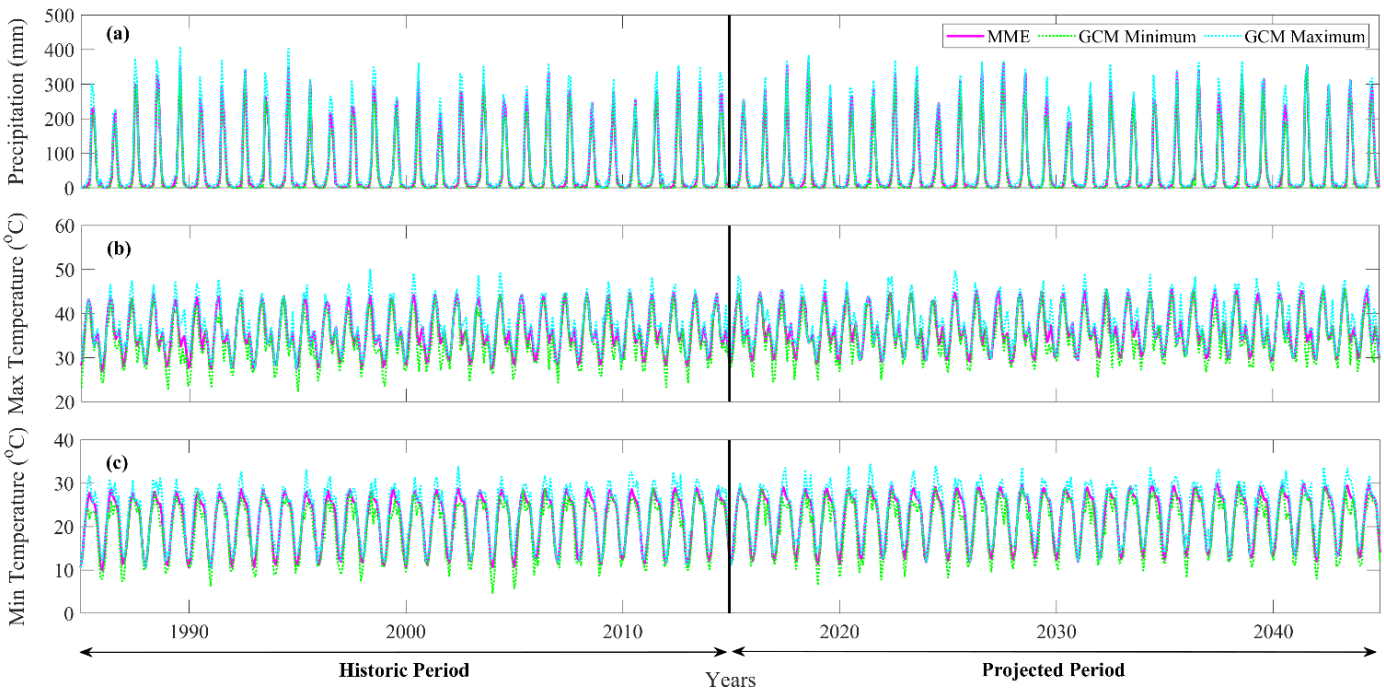

Figure 2. Time series of maximum and minimum values of global climate model (GCM) and the multi-model ensemble (MME) mean for the Araveli region (AV). (a) Precipitation; (b) maximum temperature; (c) minimum temperature.

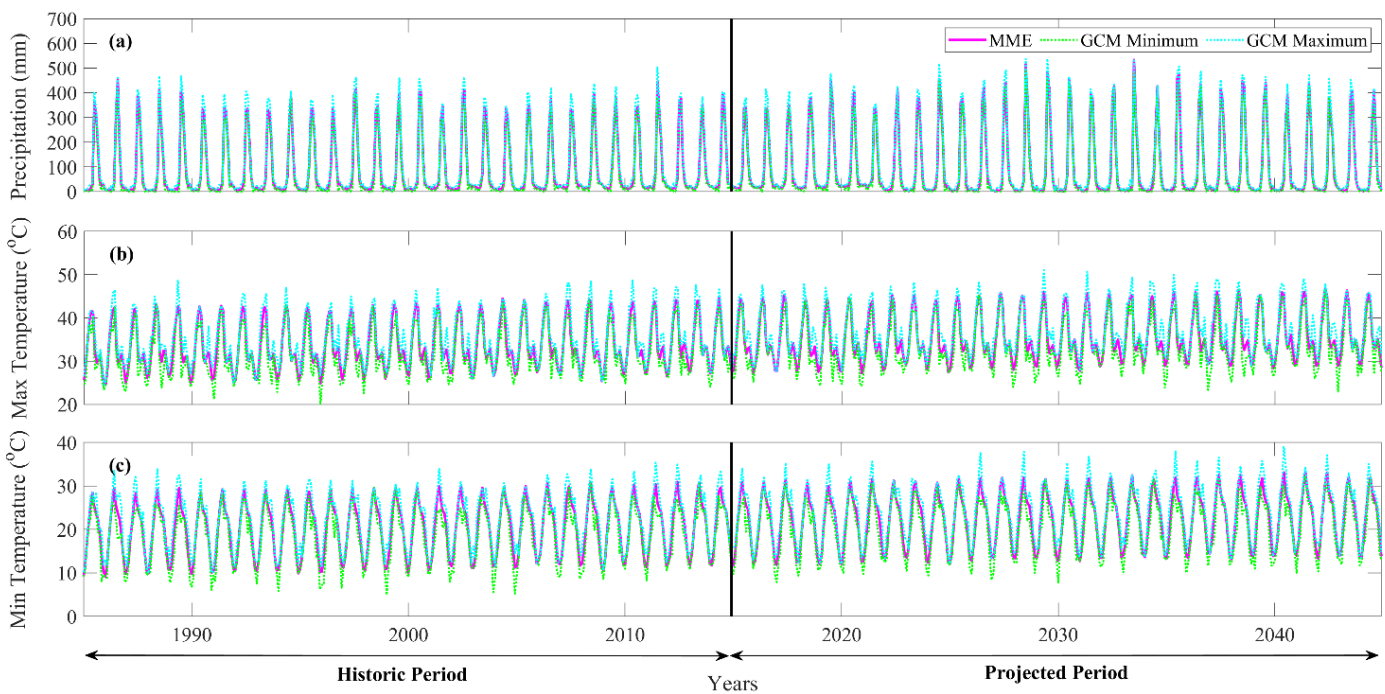

Figure 3. Time series of maximum and minimum values of GCM and the MME mean for the Bundelkhand region (BK). (a) Precipitation; (b) maximum temperature; (c) minimum temperature. 


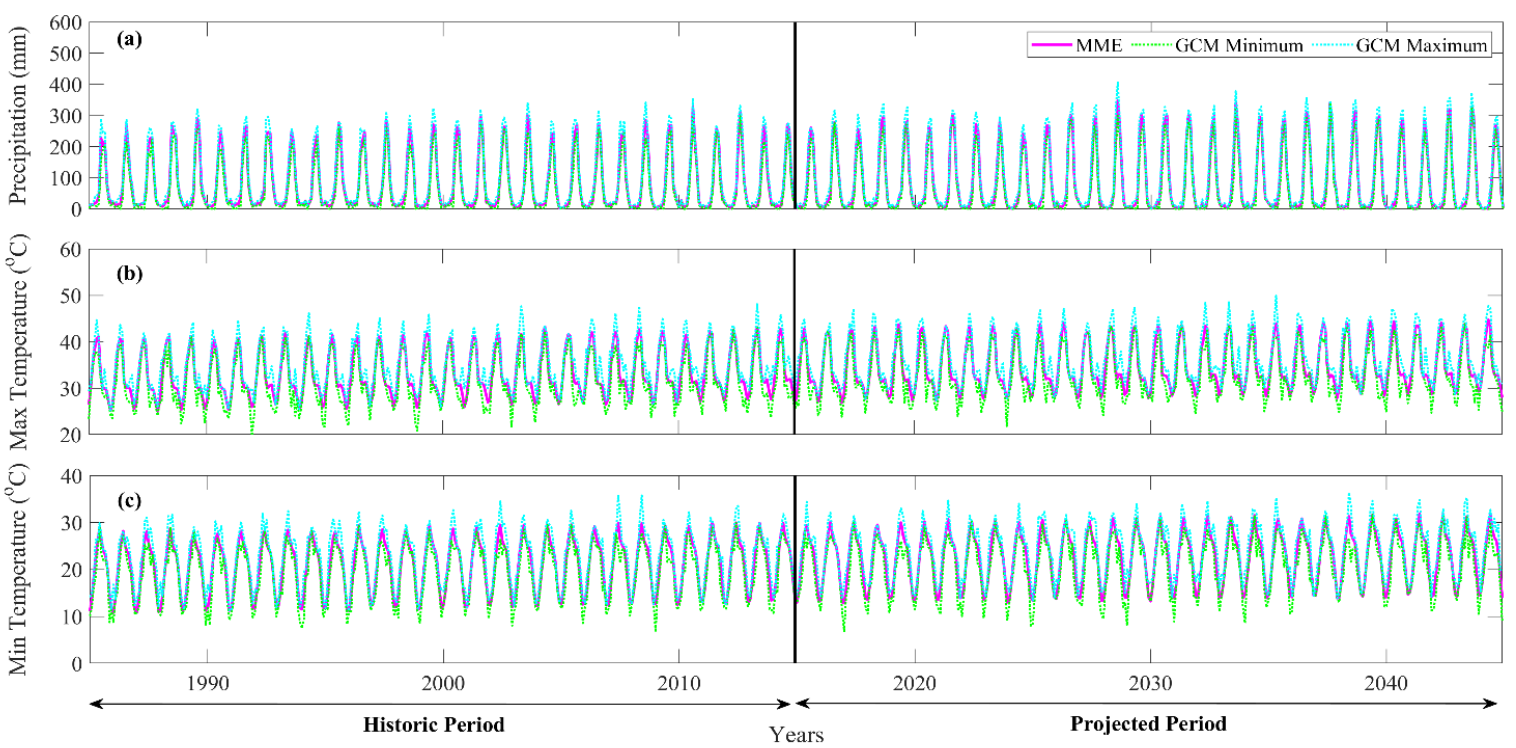

Figure 4. Time series of maximum and minimum values of GCM and the MME mean for Kansabati river basin (KSB). (a) Precipitation; (b) maximum temperature; (c) minimum temperature.

\subsection{Methodology}

\subsubsection{Bias Correction of Climate Variables}

The gridded CMIP6 climate variables at various spatial resolutions were initially re-gridded to a target resolution of $1 \mathrm{~km}$ using bilinear interpolation. Bilinear interpolation is a method for computing values of a grid-based on a weighted average of four nearby grid cells. The weightage is applied depending upon the distance of the nearest cells ensuring the smoothing of the output grids. Furthermore, an MME mean of each of the climate variables were computed for simplicity and to lessen the variance of the ensemble datasets. All available simulation output from 7 different climate models for respective scenarios were considered.

To bias-correct the bilinearly interpolated CMIP6 future data, observed historical data with identical spatial resolution is required. Identical spatial resolution results in an accurate and easier grid to grid computation. A part of this study was to generate bias-corrected future climate data at a $1 \times 1 \mathrm{~km}$ resolution, but no historical data was available with that finer resolution. Therefore, the delta method of downscaling was used to develop observed historic gridded data (1985-2014) with a spatial resolution of $1 \times 1 \mathrm{~km}$ for both temperature and precipitation. In this approach, bilinear interpolation was performed on Berkeley earth surface temperature data, while maintaining a similar anomaly (1970-2000) to that of Worldclim2 temperature, to generate historically observed temperatures (both maximum and minimum) at $1 \mathrm{~km}$ resolution. To bias-correct and refine the finer scale temperature data, a method proposed by Leander and Buishand [51] was used. Meanwhile, to generate a fine-scale $(1 \times 1 \mathrm{~km})$ observed historical precipitation data, a two-step technique was formulated. At first, quantile mapping [52] was applied to rectify the bilinearly interpolated $\left(0.05^{\circ} \times 0.05^{\circ}\right)$ Global Precipitation Climatology Centre version 7, in association with the Climate Hazards Group Infrared Precipitation dataset. Secondly, the rectified data from the first step and Worldclim2 (1970-2000) precipitation were used to generate $1 \times 1 \mathrm{~km}$ resolution precipitation data, employing the same process as that for temperature. A complete explanation of the methodology can be found in Herrera et al. [53].

The primary focus of this work is to predict future droughts using monthly temperature and monthly precipitation from the climatic models. Therefore, the downscaled MME mean of the 
precipitation and temperature for each of the scenarios was bias-corrected using the equidistant quantile-based mapping (EDCDFm) proposed by Li et al. [49], as shown in Equation (1).

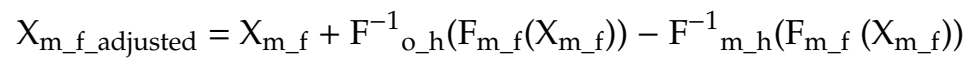

$m$ = MME mean of CMIP6 data

$f=$ future observations from CMIP6 (2015 to 2044)

$o=$ historical observations from CMIP6 (1985 to 2014)

$h=$ observed historical data from gridded data (1985 to 2014)

$X=$ climate variables $\left(\operatorname{Tas}_{\max }, \mathrm{Tas}_{\min }\right.$, and $\mathrm{Pr}$ )

$F=$ cumulative distributive function $(\mathrm{CDF})$

$F^{-1}=$ inverse cumulative distributive function

The EDCDFm method works in such a way that the relative difference between the CMIP6 values and observed values in the historical period remains the same for the future period so that the adjustment function also continues to be the same. All the while, the differences among the CDFs of the future, as well as historical periods, are also taken into consideration. In Equation (1), $\mathrm{F}_{\mathrm{o} \_\mathrm{h}}$ and $\mathrm{F}_{\mathrm{m} \_\mathrm{h}}$ are the CDF of observed and MME mean of CMIP6 outputs at a given grid for historical time period, respectively. $F_{m_{-} f}$ is the equivalent $C D F$ of $F_{m_{-} h}$ for the future. $X_{m_{-} f}$ represents the MME mean of CMIP6, while $\mathrm{X}_{\mathrm{m} \_\mathrm{f}}$ adjusted represents the future bias-corrected output.

The method was carried out in the individual grid cells such that the probability density function (PDF) for simulated climate variables were transferred to the PDF derived based on observed historically gridded data. Here, the EDCDFm method took the differences of PDF in between CMIP6 historical and future data. The steps involved to complete the bias correction is sequentially shown in Figure 5. To make sure that the interpolation between the values of the empirical CDFs does not occur, the parametric distributions were shaped to the climate data at each grid following the same procedure as implemented by Li et al. [49]. The method first finds the biases in the historical period (1985-2014) and then rectifies the future period (2015-2044) for all climate variables.

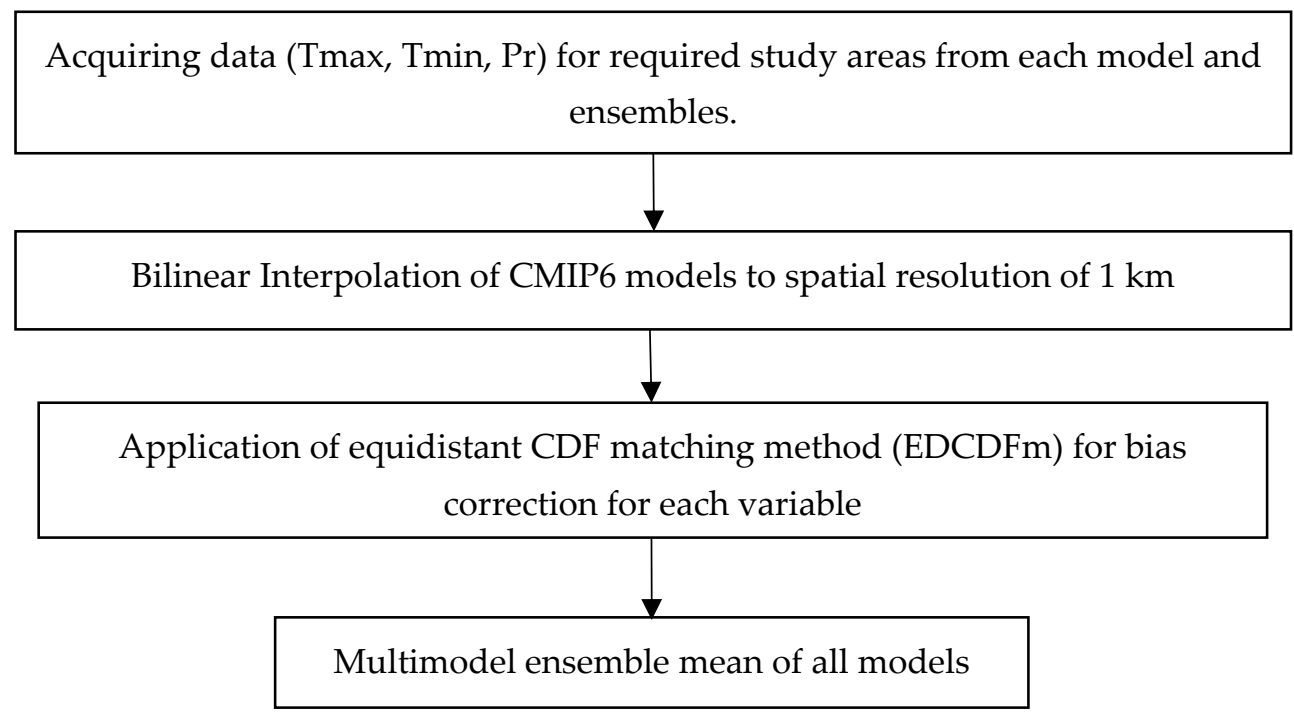

Figure 5. Outline of bias correction steps with applied methods.

\subsubsection{Potential Evapotranspiration}

The drought index used in this work takes into account the evaporative demand of the atmosphere. For our work, the simple and physically relevant Penman-Monteith (PM) method is implemented compared to the Thornthwaite method of calculation. The PM method is a way to compute 
evapotranspiration from meteorological records. It computes evapotranspiration based on daily mean temperature, solar radiation, wind speed, and relative humidity. The PM method is applied here because of its ability to compute potential evapotranspiration (PET) based on a diverse set of data, unlike the Thornthwaite method, which is dependent on inputs such as mean temperature and latitude. The PM method is physically robust, even though the Thornthwaite equation is developed entirely dependent on precipitation [54]. However, it is a notable fact that the latter method results in overestimated values of PET in a warmer climate [55]. Moreover, the capability of the PM method to calculate PET even without climate data over a prolonged period of time makes it a preferable option to use. The reference crop evapotranspiration is based on the Food and Agriculture Organization (FAO)-endorsed PM parameterization [56,57].

$$
P E T=\frac{0.408 \Delta(R n-G)+\gamma \frac{900}{T+273.16} U_{2}\left(e_{s}-e_{a}\right)}{\Delta+\gamma\left(1+0.34 U_{2}\right)}
$$

where $\mathrm{Rn}$ is the net radiation, $\mathrm{G}$ is the soil heat flux density, $\mathrm{T}$ is the mean temperature measure at $2 \mathrm{~m}$ of height, $U_{2}$ is the velocity of wind measured at $2 \mathrm{~m}$ of height, $\left(\mathrm{e}_{\mathrm{s}}-\mathrm{e}_{\mathrm{a}}\right)$ is the vapor pressure difference at $2 \mathrm{~m}$ height, $\Delta$ is the gradient of the vapor pressure curve, and $\gamma$ is the psychrometric constant. The value of the wind coefficient for the reference crop is taken as 0.35 and the coefficient for the reference crop is $900 \mathrm{KJ}^{-1} \mathrm{kgKday}^{-1}$.

Climate variables such as the monthly mean of daily maximum, mean and minimum temperatures, wind velocity, and cloud cover were used to calculate PET. Along with temperature and precipitation, CMIP6-based future (2015-2044) cloud cover and wind velocity were downscaled and bias-corrected to the spatial resolution of $1 \times 1 \mathrm{~km}$ before estimating PET. National Centers for Environmental Prediction-National Center for Atmospheric Research-based cloud cover and Climate Research Unit (CRU) wind speed climatologies were used as the historical observation dataset (1985 to 2014) to bias-correct CMIP6-based future cloud cover and wind speed data based on Li et al. $[49,53]$. The temperature values, windspeed $\left(\mathrm{U}_{2}\right)$, and the vapor pressure deficit were measured at $2 \mathrm{~m}$ height. The vapor pressure here is the difference between actual vapor pressure $\left(e_{a}\right)$ and saturation vapor pressure $\left(e_{s}\right)$. Monthly means of saturation vapor pressure were estimated from the formula for vapor pressure.

$$
e(T)=0.6108 \exp \left(\frac{17.27 T}{T+237.3}\right)
$$

Saturation vapor pressure can contain some bias because of the nonlinear nature of Equation (3) and the presence of which can be checked by making a comparison between averaged temperature computed from both the maximum and minimum temperatures and the mean temperature. When the difference between two of the average temperatures is considerably less, the presence of bias can be neglected in the vapor pressure. Likewise, the actual vapor pressure was also computed by minimum temperature due to the limited record of suitable humidity and dewpoint temperature, similar to the process followed in [58]. This process applied here may not fare well for semiarid and arid regions, but, while matching our PET estimates with the CRU PET product, the process performed well.

\subsection{3. scPDSI Drought Index}

scPDSI is a popular drought index that is extensively used to quantify drought variations and long-term changes with an improved understanding of spatial distribution in various local and global scales. Palmer developed the index in 1965, which contained deficiencies such as rational sensitivity towards the calibration period along with spatial incompetency to predict the drought distribution [59]. Overcoming these shortcomings, the self-calibrating Palmer Drought Severity Index was developed by Wells et al. [60]. The new drought index provided an edge over the older one, such that by tuning the index to suit the local conditions, the climatic variability would be comparable over any given study area. Further details concerning the development of the scPDSI can be found in Wells et al. [60]. 
The drought index was computed based on MME mean of monthly estimates temperature and precipitation as well as the time series of monthly PET values from 2015 to 2044 . A calibration period from 2015-2044 was defined to establish hydroclimatic conditions that match the actual condition of the study area. Calibration here refers to the scaling of the scPDSI algorithm to define its distribution approximately between -4 and +4 (extreme values of scPDSI). The aim of the calibration period is to contain severe droughts to adjust these occurrences to the extreme scPDSI values. The calibration period in this work was defined with regards to the anthropogenic effect on climate change and to be closely consistent with the CMIP6 dataset. Likewise, the initial condition regarding the soil moisture was set to $100 \%$ of available water content during the calculation of scPDSI. It is done because, unlike other drought indices, scPDSI considers the soil properties for the drought quantification. This calculation was completed through a script set available in the R program for scPDSI.

\subsubsection{Future Duration of Drought}

Future duration of drought here refers to the number of months; a study area might face droughts of different levels of severity in the near future (2015-2044). The scPDSI-based future drought estimation based on three CMIP6 scenarios is made the focus in this research work to show the relative differences in the occurrence of drought in each of the scenarios. Since each drought situation will last for a specific length with a certain level of severity for each scenario, necessary mitigation steps can be adopted to avoid or best mitigate such calamities. The aim is also to show how the scenarios defined by the latest CMIP6 relates to actual emission levels, land use situation, and societal conditions, which are the basis of its development. The levels of severity considered for the future duration of droughts are severe $($ scPDSI $<-3)$ and extreme droughts (scPDSI $<-4)$ [53]. The drought period in the future is studied comparatively with the drought in the historic period obtained using the observed historical dataset from 1985 to 2014.

\section{Results}

The duration of drought in the future thirty years is displayed through varying maps that allow us to identify major drought-prone areas. The aim is to provide relevant information to aid in the resiliency of such areas before and during said drought through proper management of water resources. The time period of the drought index is for a thirty-year period, which is referred to as the near future and is presented for each of the CMIP6 scenarios.

\subsection{Araveli Region}

The distribution of future drought duration is similar throughout the study area for most of the scenarios. However, severe drought under the SSP5-8.5 scenario yields different durations all over AV. The majority of the grids in AV region under the severe drought (scPDSI $<-3$ ) are expected to face droughts of around 10 months in the near future under the SSP1-2.6 scenario, as shown in Figure 6a. Almost all of the AV under the same scenario for extreme drought (scPDSI $<-4$ ) shows a fairly constant duration of drought, as shown in Figure $6 \mathrm{~b}$. As per the temporal plot of grid averaged scPDSI values in Figure 7a, severe droughts are expected around 2018 and 2025 for a year while a sustained drought period is expected during the mid-2030s. A very few numbers of grids points on the northern side of $\mathrm{AV}$ particularly in Ajmer district show around 25 months of severe drought on average during the entire thirty years of future under the SSP1-2.6 scenario. Likewise, few grid points in the southeastern side of the region, particularly in the Chittauragarh district, show a drought duration of around 20 months. Seemingly, a longer duration of severe drought is found in areas other than the central area. Udaipur district that is almost entirely in the central area is less drought-prone, which makes sense since the central area generally receives more rain compared to the other parts of the region. Extreme drought is expected to persist in the early half of the 2030s, as seen in Figure 7a. The extreme drought condition (scPDSI < -4) under SSP1-2.6 is found to last around 5 to 10 months in the near future in the majority of the AV region, as shown in Figure $6 \mathrm{~b}$. Interestingly, there also 
exist such grids in AV that face no extreme drought at all, which are found in the extreme northern part. Hence, it can be considered that the future drought condition may not be devastating under the SSP1-2.6 scenario as compared to droughts faced by the same region around 1984 till 1987 [61].
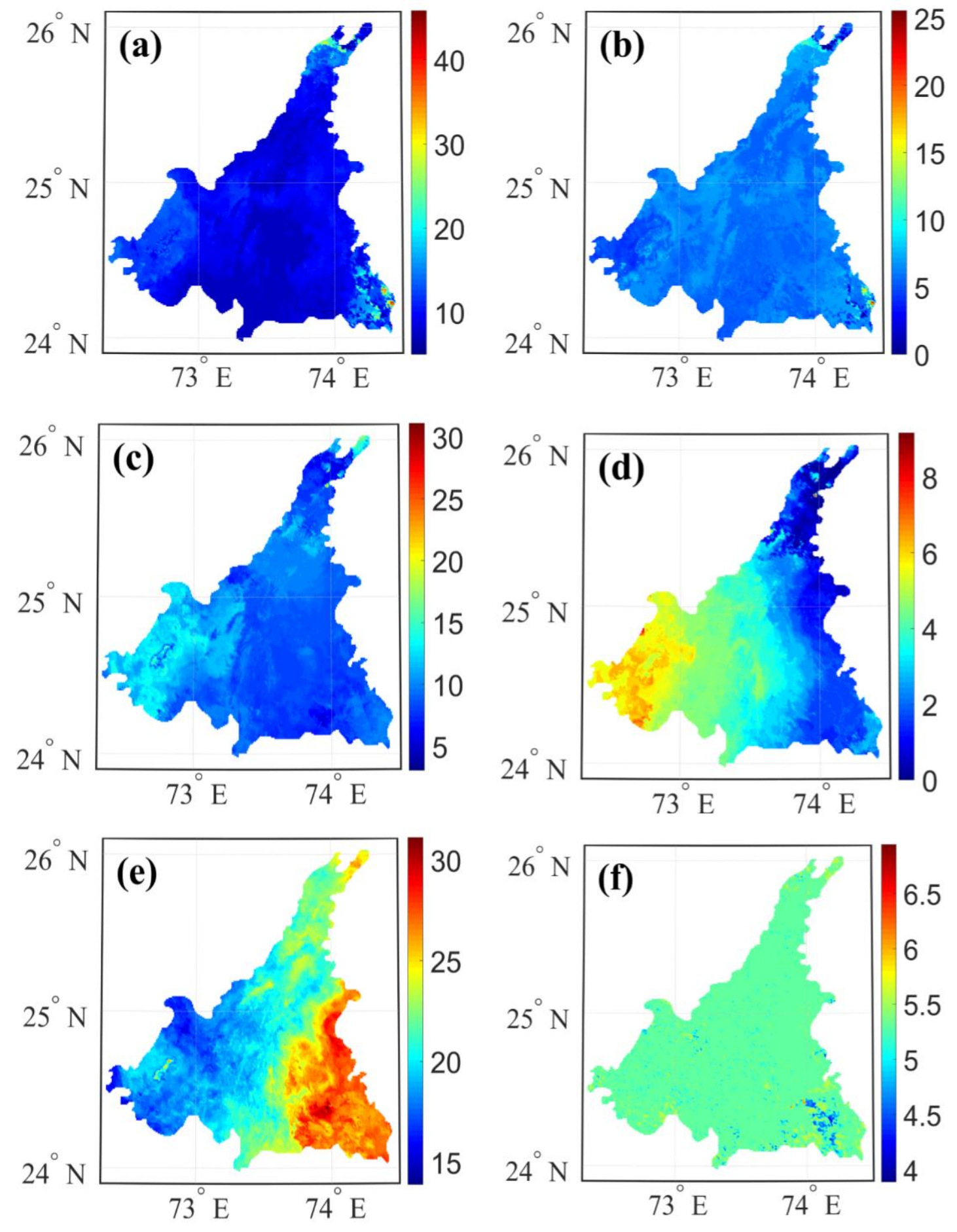

Figure 6. Drought duration maps for each Coupled Model Intercomparison Project Phase 6 (CMIP6) scenario for study area AV. (a,b) for SSP1-2.6; (c,d) for SSP2-4.5; (e,f) for SSP5-8.5. (a,c,e) for severe drought and $(b, d, f)$ for extreme drought. The scale bar represents months of drought in 30 years (2015-2044). 

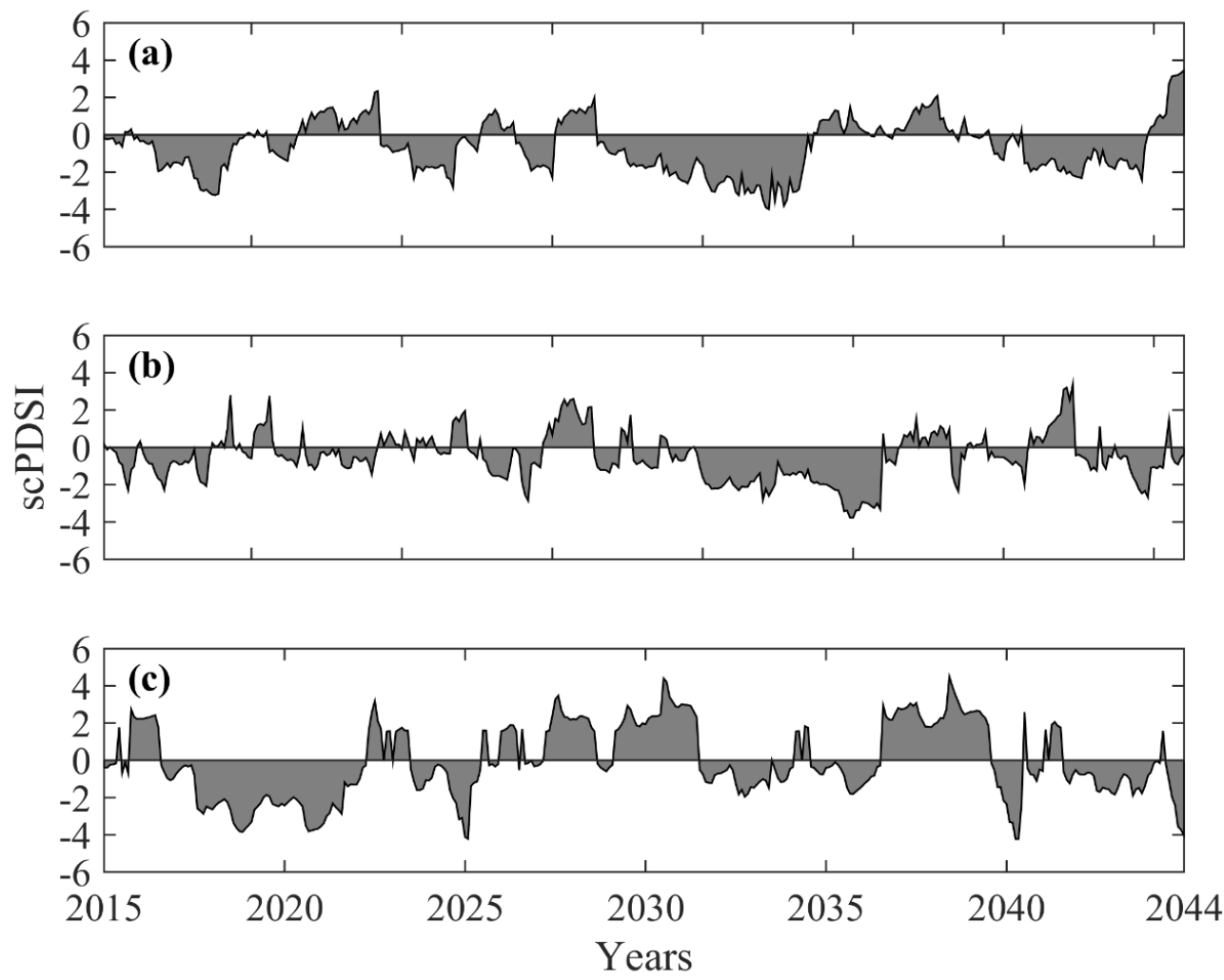

Figure 7. Grid-averaged self-calibrating Palmer Drought Severity Index (scPDSI) values from 2015-2044 for study area AV. (a) scPDSI values for SSP1-2.6; (b) scPDSI values for SSP2-4.5; (c) scPDSI values for SSP5-8.5.

Relatively diverse drought periods are evident under the SSP2-4.5 scenario compared to SSP1-2.6. For severe droughts under the SSP2-4.5 (Figure 6c), the western half of the study area is expected to face around 13 months of drought in the near future. The rest of the area of AV may face severe drought periods of less than 10 months in the near future. The overall region is likely to face 12 months of severe drought periods on average, although higher severe drought periods are expected in eastern AV compared to western AV under the SSP1-2.6 scenario. The temporal plot of grid averaged scPDSI in Figure $7 \mathrm{~b}$ shows the persistence of severe to extreme drought during the first half of the 2030s under the SSP2-4.5. Other than that, very few grids of the study area are expected to face a severe drought period of around 20 months. These grids lie in the northern extreme end of the study area. The extreme drought durations are expected to have maximum values in western AV denoted by yellow and red patches in Figure 6d. This can be attributed to the presence of desert areas around the western half of the AV. Compared to SSP1-2.6 and SSP2-4.5 scenarios, severe and extreme drought durations are expected to be varying all over the study area.

Unlike other scenarios, under SSP 5-8.5, the lengthiest extreme drought duration is expected in the eastern part of AV (Figure 6e). Also, based on grid averaged scPDSI in Figure 7c, the majority of the severe to extreme droughts under the SSP5-8.5 scenario are expected between 2018 and 2025 . The severe drought duration under SSP 5-8.5 is expected to be higher in eastern AV compared to western AV of the study area. Around the eastern part, the total average duration of severe drought is expected to be around 28 months in the near future, as shown in Figure 6e. This duration of severe drought is expected to be around 22 months along the central region in districts such as Ajmer and Udaipur, which can be observed in Figure 6e. The extreme western area of AV, which is the Sirohi district, is expected to face severe drought duration spanning about 15 months in the near future, while the extreme drought duration seems to remain constant throughout the whole region with a very small duration of around seven months in the near future. This can be considered less harmful considering the extreme drought durations which are expected in previous scenarios. Also, Bhuiyan et al. [61] 
accounted for extreme droughts for over 36 months from 1984 till 1987 and the year 2000 in AV. Based on this, seven months of extreme drought in the near future seems less concerning. From Figure $6 \mathrm{f}$, the duration of extreme drought is expected to remain nearly spatially uniform throughout the study area. An exception is denoted by blue patches in the eastern region, particularly in the Chittauragarh district. The extreme drought duration is found to be minimal in the same district with a duration of around four months on average in the near future.

\subsection{Bundelkhand Region}

Based on the analysis of future drought, the duration of severe drought events under the SSP1-2.6 scenario is expected to last between 10 and 40 months in the near future (Figure 8a). The climate of the Bundelkhand region is a hot semi-humid region. Districts like Banda, Chattarpur, and Sagar are usually expected to have worse drought situations with relatively longer duration due to their records of higher temperatures. However, the Banda district, which lies in the extreme east end of Bundelkhand according to the analysis, is expected to face drought duration between 20 and 30 months (Figure 8a), whereas the Chattarpur district, which lies in the central Bundelkhand, is expected to face severe drought duration between 30 and 40 months in the near future. The indication of 40 months of severe duration is expected in a lesser number of grids lying in the central and eastern part of the study area denoted by red patches in Figure 8a. These grids lie around the districts such as Tikamgarh, Panna, and Chattarpur. On the other hand, extreme drought events (scPDSI $\leq-4$ ) are expected to last for fewer months compared to severe drought (Figure 8b). Almost all of the region except the central region of the study area is expected to face an extreme drought of at most five months. Hence, in the near future under the SSP1-2.6 scenario, if the emissions induce radiative forcing of $2.6 \mathrm{~W} / \mathrm{m}^{2}$, the extreme drought situation may have the least implications as extreme to severe droughts of 3-5 months is prevalent based on the past record (1976-2009) of the study area [62]. Also, Figure 9a shows that a good half of the 2020s is expected to face severe to occasional extreme drought situations. The duration of both severe and extreme droughts according to the analysis is almost similar for both SSP1-2.6 and SSP2-4.5 scenarios which can be seen in Figure $8 \mathrm{a}, \mathrm{c}$ and Figure $8 \mathrm{~b}, \mathrm{~d}$, respectively. However, the difference in the spatial distribution of the duration of droughts throughout the study area is noticeable in both cases.

While under the SSP1-2.6 scenario, a relatively diverse distribution of severe drought period is expected, under the SSP2-4.5, the majority of the area in Bundelkhand is expected to face a constant duration of droughts. Severe droughts of duration between 10 and 20 months and extreme drought of 5 and 10 months in the near future are expected as per Figure $8 c, d$, respectively. However, prolonged severe droughts of duration 30 to 40 months in the near future is expected in the eastern side of the study area, particularly in the Banda and Panna district (Figure 8c), which are well known for hot surging temperatures in recent years. Rather shorter durations of extreme droughts are expected under the SSP2-4.5 scenario (Figure 8d) in the majority of the BK, which indicates a lesser risk in the future, although some regions lying in the eastern part, which is the Panna district, is expected to face extreme drought duration of around 15 months in the near future. With these observations, it can be stated that under the SSP2-4.5 scenario, the drought durations will be shorter in the majority of the area compared to the SSP1-2.6. The extreme and severe droughts under the SSP2-4.5 scenario are expected mostly after 2030 but intermittently, as shown in Figure 9b. A series of dry and wet periods can be observed in the near future.

A comparatively lesser duration of drought is expected under the SSP2-4.5 scenario in the majority of the study area. However, under the SSP5-8.5 scenario, prolonged duration of severe drought with duration ranging between 25 and 35 months is expected in the near future. The majority of the study area is expected to be under the longer duration of severe drought and more pronounced drought duration in western districts such as Lalitpur and Tikamgarh (Figure 8e) with the duration of drought averaging 32 months in 30 years of time. Shorter duration of severe droughts is expected in the southern region of the Bundelkhand, particularly in the Sagar district, with a duration averaging 23 months in the near future. Apart from the southern extreme regions, other regions are expected to face a severe drought of more than 25 months. Although severe drought duration is expected to last 
between 2 to 3 years, the duration of extreme drought in any of the scenarios is shorter, and SSP5-8.5 is no exception. The longest duration of extreme drought that is expected to occur in the BK under the SSP5-8.5 scenario is a total of 6 months in the near future. As per Figure 9c, the droughts are not long enough to pose significant harm in 30 years. The majority of the area in BK except for the outskirts of the Jalaun district in the northern region is expected to face an extreme drought of around 5 months, as shown in Figure 8f. The extreme drought duration under SSP5-8.5 is similar in all scenarios in the majority of the area, while some parts of BK show a much longer duration of extreme drought. These durations can be considered ineffective over the thirty years of duration based on past records of drought in the study area [62].
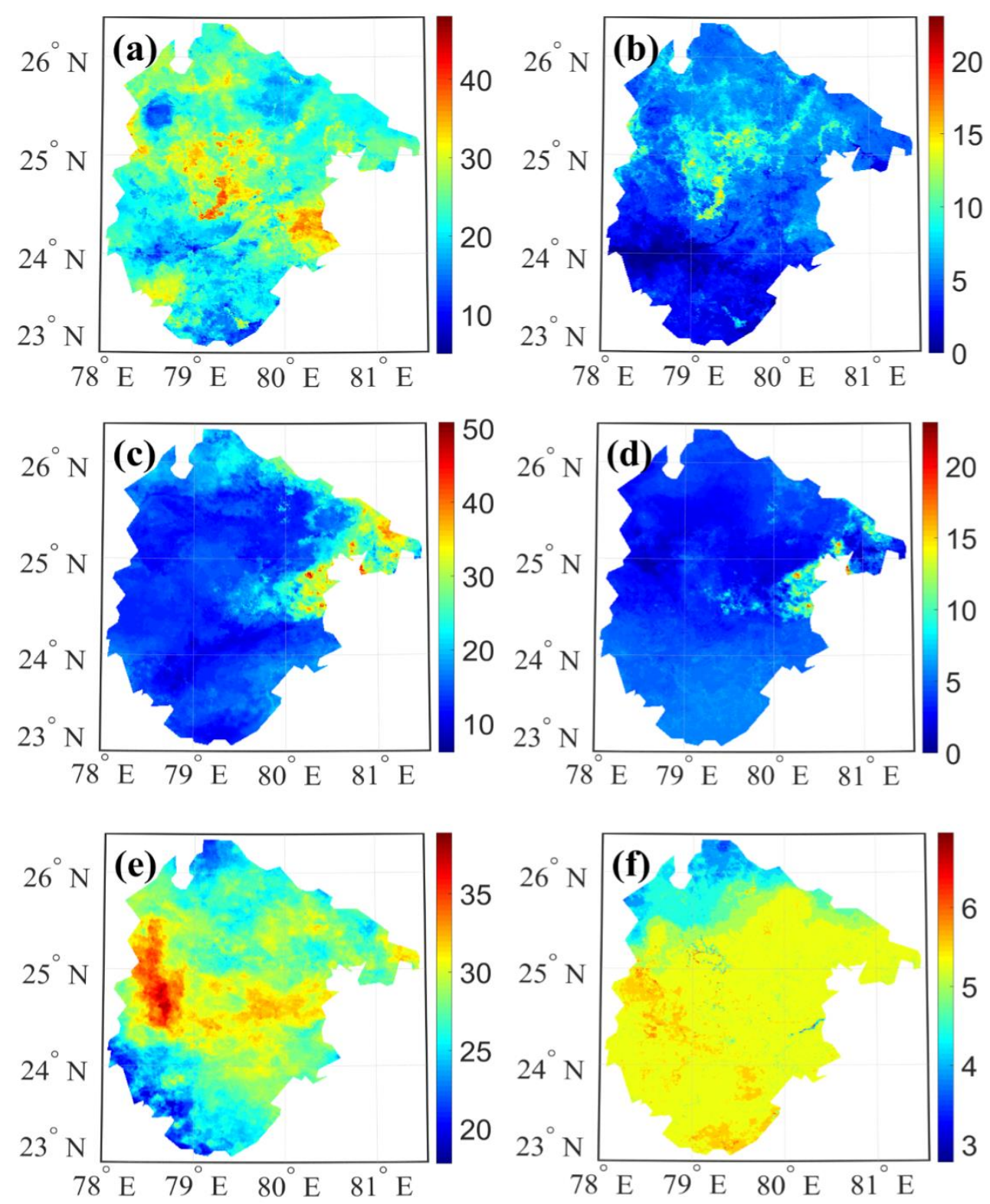

Figure 8. Drought duration maps for CMIP6 scenarios for study area BK. (a,b) for SSP1-2.6; (c,d) for SSP2-4.5; (e,f) for SSP5-8.5. (a,c,e) for severe drought and $(\mathbf{b}, \mathbf{d}, \mathbf{f})$ for extreme drought. The scale bar represents months of drought in 30 years (2015-2044). 

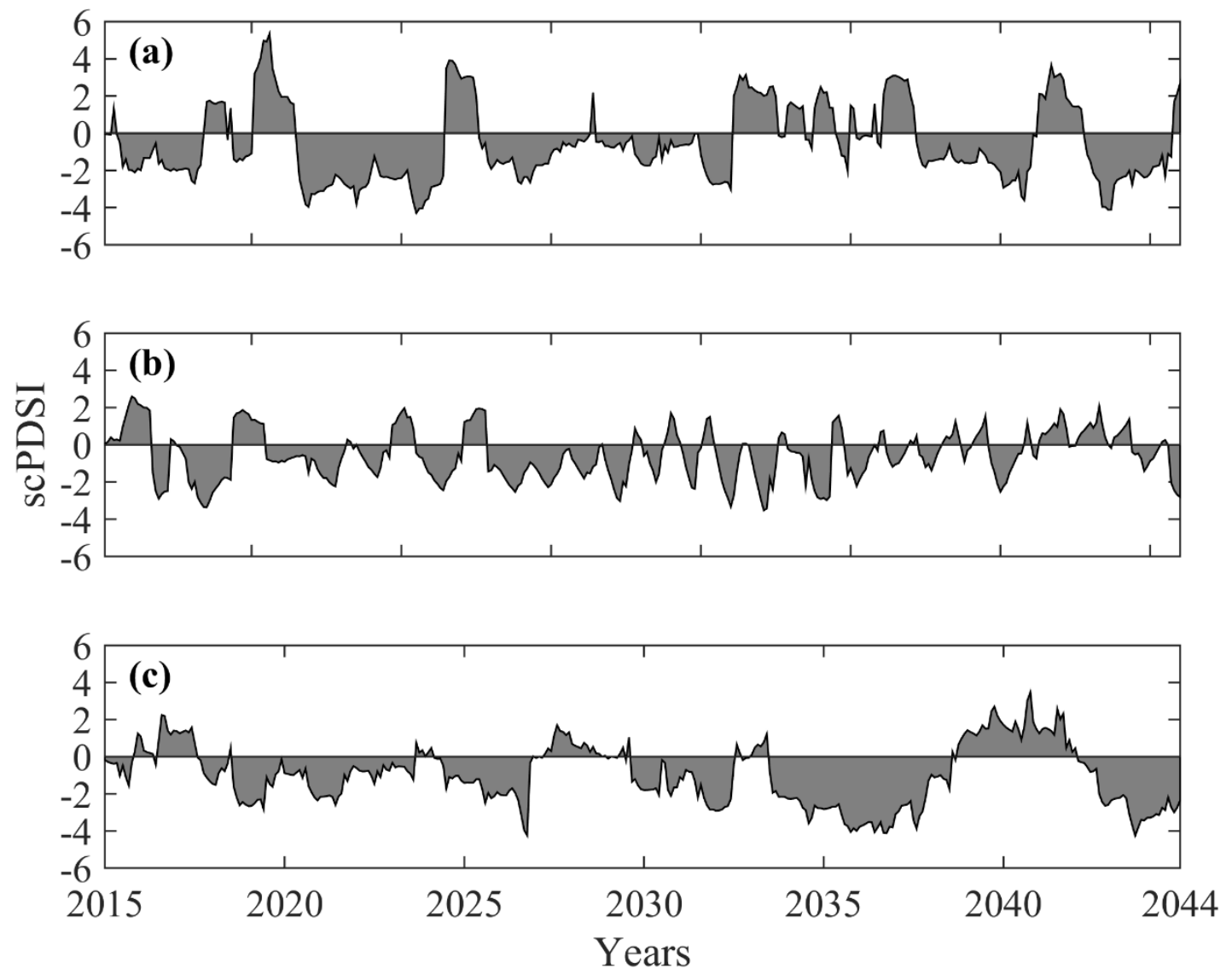

Figure 9. Grid averaged scPDSI values from 2015 to 2044 for study area BK. (a) scPDSI values for SSP1-2.6; (b) scPDSI values for SSP2-4.5; (c) scPDSI values for SSP5-8.5.

\subsection{Kansabati River Basin}

The distribution of severe drought duration is spread randomly over the study area. The duration is expected to range between 10 and 40 months under the SSP1-2.6 scenario. The severe drought duration of around 40 months in the near future is found in around central-northern half of the study area and the extreme southern regions denoted by red patches in Figure 10a. The study area experiences very hot summers and the temperature reaches $45^{\circ} \mathrm{C}$ in the months of May and June, which gives an idea that the climatic conditions are favorable for drought. In Purulia district that lies in the upper northern half of the study area, the severe drought durations are expected to last around 10 to 35 months approximately. The uneven distribution of drought duration throughout the study area, rather than a belt of similar drought durations, shows the efficacy of the spatial resolution of the drought data. It also can be attributed to the climatic variability in the study area, but the variation of the drought duration obtained through the analysis shows the actual application of high spatial resolution.

The spatial distribution of durations of both extreme and severe drought under SSP1-2.6 is similar but with different durations. It is evident in Figure 10a,b, with red patches denoting the upper limit of drought durations highlight similar regions. From this, it can be inferred that places where severe drought lasts for a longer time eventually turn into an extreme drought situation. The maximum duration of extreme drought is expected to last around 15 months in the near future. Likewise, in a similar manner like other study areas, the extreme drought situation is expected to last for a lesser duration of time compared to severe drought. In the majority of the study area, extreme drought is expected to last between 5 and 10 months, while there are also places that are expected to be unaffected by the extreme drought situation. Bankura district, which lies in the central part of the study area, 
and Purulia district, lying at the eastern extreme end, are expected to face little or no extreme drought. Under the SSP1-2.6 scenario, severe and extreme droughts can be expected every decade with a fairly lengthy spell during the early 2030s, as seen in Figure 11a.
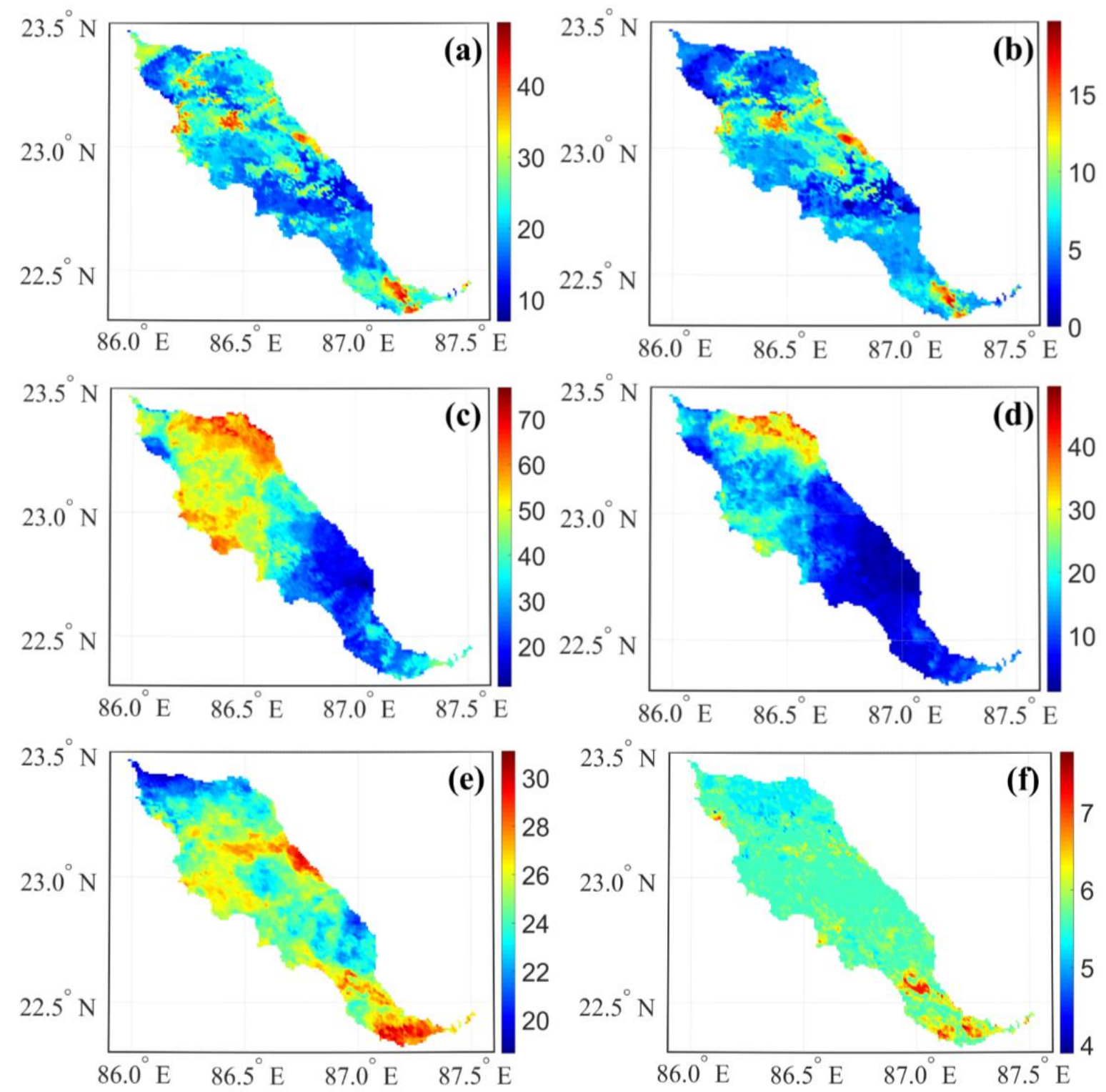

Figure 10. Drought duration maps for CMIP6 scenarios for study area KSB. (a,b) for SSP1-2.6; (c,d) for SSP2-4.5; (e,f) for SSP5-8.5. (a,c,e) for severe drought and $(\mathbf{b}, \mathbf{d}, \mathbf{f})$ for extreme drought. The scale bar represents months of drought in 30 years (2015-2044).

Under the SSP2-4.5 scenario, the severe and extreme drought durations are found to be very similar which is unusual compared to other scenarios and study areas. The severe drought duration can be expected to last between 20 and 60 months. The Purulia district in the northern half of the study area, according to the analysis, may face droughts ranging between 40 and 60 months. The SSP2-4.5 scenario, which accounts for higher emission rates and increased land use patterns compared to SSP1-2.6, can be a cause for droughts of longer duration according to the analysis results. Severe drought duration of around 20 to 30 months can be expected in the southern central half of the study area (Figure 10c). Over 60 months of severe drought in the near future is the longest duration of drought that can be expected. The drought durations obtained under SSP2-4.5 are expected to be distributed evenly compared to drought durations under SSP1-2.6. An extreme drought duration of 10 months is expected 
to be dominant in the lower half of the study area, as shown in Figure 10d, while chances of no extreme drought also exist. The duration of extreme drought can be expected to higher in the lower half of the study area compared to the upper half. The upper north regions of the Kansabati region filled with cyan patches and few of the grids filled with red patches denote the extreme drought duration ranging between 20 and 40 months. Unlike any other cases, the extreme drought duration under SSP2-4.5 for this study area is concerning in regards to a seemingly longer duration of extreme drought of around 30-40 months. In the occurrence of such a scenario, the conditions can be difficult to recover from because a long term drought faced by the study area in the past lasted for 22 months [63]. Severe to extreme drought can be expected after 2015 till the early 2020s, as per Figure 11b, although a significant wet period can be expected after 2021, which can end around 2035.
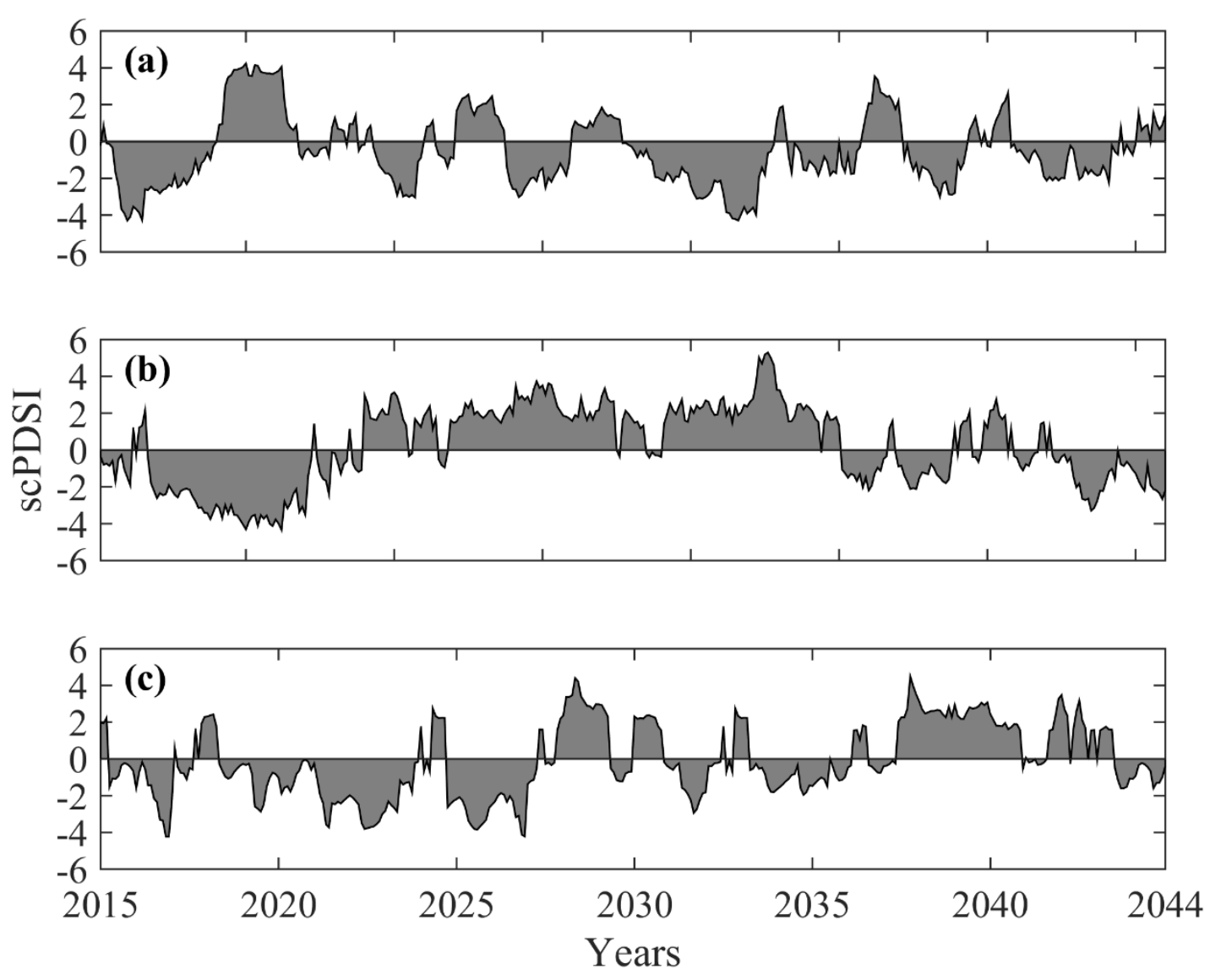

Figure 11. Grid averaged scPDSI values from 2015 to 2044 for study area KSB. (a) scPDSI values for SSP1-2.6; (b) scPDSI values for SSP2-4.5; (c) scPDSI values for SSP5-8.5.

Under the SSP5-8.5 scenario for severe drought conditions (Figure 10e), the longer drought duration is expected to last around 27 to 30 months in the near future. The severe to extreme droughts are observed to take effect during the 2020s, with some brief wet spells as per the temporal plots of grid averaged scPDSI values (Figure 11c). Spatially, the longer duration of severe drought can be found abundantly in the lower half of the study area (Figure 10e). In the extreme lower end, dark red patches show, on average, 30 months of severe drought duration. Apart from the extreme lower end, the longest duration of severe drought can be found in the central part of the study area, as shown in Figure 10e. Shorter duration of severe drought under the SSP 5-8.5 scenario is evident in many other locations in the study area ranging from 20 to 26 months. Some locations facing the least duration of severe drought spanning around 20 months can be observed in the extreme upper end. Extreme drought conditions can be expected to last at least five months in the near future throughout the study area (Figure 10f). The duration of extreme drought is considerably less compared to severe drought duration. 
Around seven months of extreme drought under SSP5-8.5 duration can be considered unalarming since long terms droughts in KSB have lasted for 10 to 22 months in the past [63]. It also can be stated that under the SSP5-8.5 scenario, the chances of greater implications of drought situations are relatively less compared to drought situations that could occur under the SSP2-4.5 scenario.

\section{Discussion}

The current study explicitly uses the MME mean of 7 different GCMs along with its ensembles. Instead of using an individual GCM's output, using an ensemble of GCM output contributes reliable estimates, especially while considering projected climate scenarios as it comprehends a range of model uncertainties and variances [64]. As CMIP6 is still in its incipient stage, the current study includes all available GCMs for temperature, precipitation, wind speed, and cloud cover. The use of MME mean is believed to have better representativeness than an individual model by decreasing the spatial error and variability $[65,66]$. Therefore, the projected drought obtained from future precipitation and temperature can be considered to be a fair representation of all the involved GCMs with reduced uncertainty and variability.

As per the results of the analysis, the drought in the $\mathrm{AV}$ region is observed to be concerning during the 2030s in SSP1-2.6 and SSP2-4.5 scenarios. During the 2030s, although the change in precipitation is not significant, the temperature is observed to be on the rise. The AV region, which is mostly dry with desert areas, experiences the arid and semiarid climate and is expected to face a little to no change in precipitation in the near future. Gupta et al. [67] also found a similar precipitation situation during 2021-2050 compared to the historical period. The AV region, which is historically known to experience less rainfall because of the hills facing the direction of the mountains that divert the direction of the monsoon to the leeward side, can experience dry climate because of the increase in evaporative demand of air in the future. This is corroborated by comparing the drought in the near future with the historic drought. The drought duration maps shown in Figure 12 show a lesser duration of both severe and extreme drought compared to the future drought durations under almost all of the scenarios in Figure 6. It is important to note that the duration of extreme drought may not see a big change in the future. Also, the interval between severe droughts in the near future is longer and much longer between consecutive extreme droughts for both SSP1-2.6 and SSP 2-4.5 scenarios (Figure 7). However, the interval between severe to extreme droughts is fairly less in the SSP5-8.5 scenario, which is a contrasting result compared to other scenarios. On the contrary, the interval between the severe to extreme droughts during the historical period was short (Figure 13). Therefore, it can be said that droughts in the future may not be frequent but may last for a while if it appears.
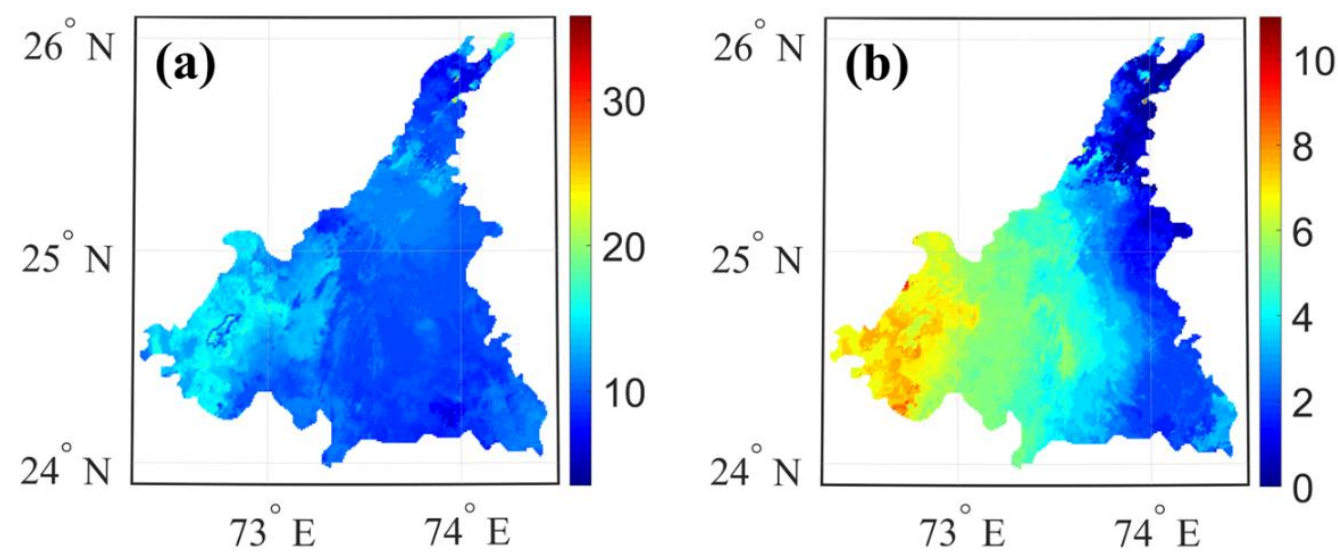

Figure 12. Drought duration maps for historic observed data for study area AV. (a) For severe drought and (b) for extreme drought. The scale bar represents months of drought in historic 30 years (1985-2014). 


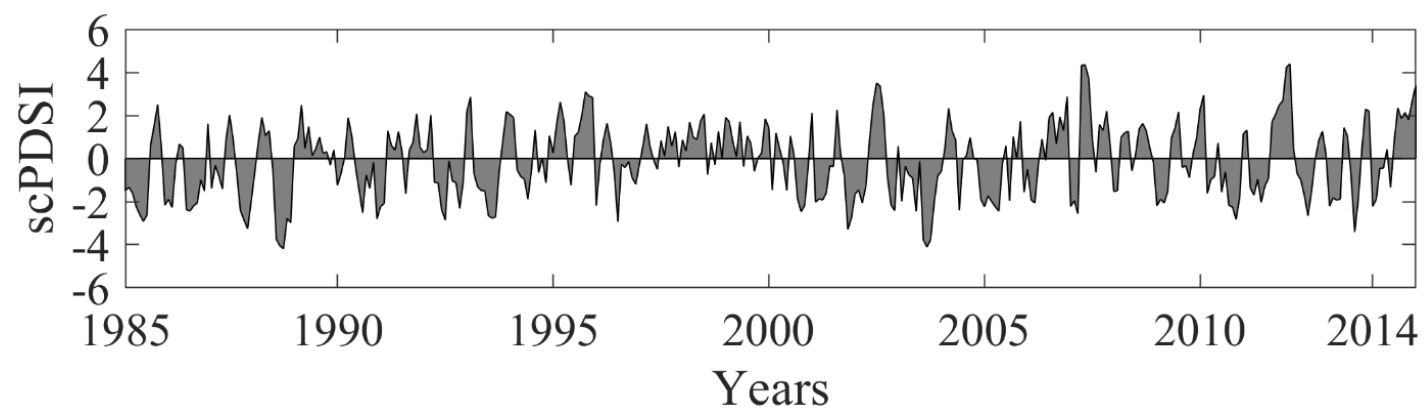

Figure 13. Grid averaged scPDSI values from 1985 to 2014 for study area AV based on historic observed data.

The future drought duration, as shown in Figure 8, is expected to increase in BK compared to the drought in the historic period. The increase in the drought duration is observed under all the scenarios but more significantly for the severe drought. The area of spread is also observed to be increasing in the near future compared to the historical period in SSP1-2.6 and SSP5-8.5 scenarios. More precisely, the increase in both the duration and the areal spread is more significant in the severe drought compared to the historical period, as shown in Figure 14. Bisht et al. [68] also exhibited an increase in Indian regions in terms of drought occurrences and the drought durations in the near future. The future drought situation can be attributed to increasing water stress under warming scenarios, which can further be related to higher evaporative demand. Further, the BK region lies in the humid subtropical region, and a rather insignificant increase in precipitation can be observed (Figure 3), and this insignificant increase in precipitation can be attributed to due to anthropogenic aerosol emissions according to Bollasina et al. [69]. However, due to the humid climate, the number of droughts faced in the near future may be frequent but not as frequent and sporadic as in the historical period (Figure 15). Similarly, Mishra et al. [70] stated that yearly variability due to sea surface temperature in the Indian Ocean could end up causing droughts in the Gangetic Plain, within which BK lies.
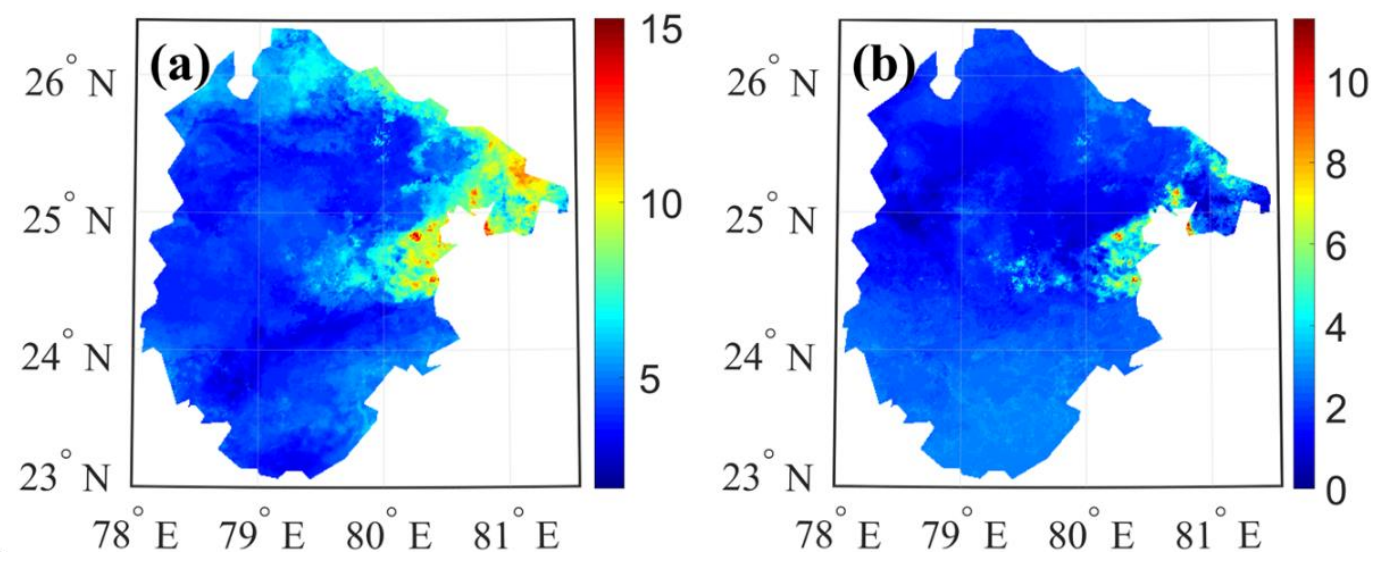

Figure 14. Drought duration maps for historic observed data for study area BK. (a) for severe drought and (b) for extreme drought. The scale bar represents months of drought in historic 30 years (1985-2014).

The drought duration in KSB is observed to be increasing significantly in the near future compared to the historical period (Figure 16). Even though an increase in precipitation is observed during the projected period, the drought duration is still expected to be on the rise based on Figure 10. This can be attributed to the subsequent increase in the evapotranspiration demand, along with the increasing projected temperature [71]. The KSB region also lies in the Gangetic Plain and is expected to face the drought in the future, according to Mishra et al. [70]. The severe and extreme droughts are more frequent in the SSP1-2.6 and SSP5-8.5 scenarios over the projected period. However, compared to the 
historic drought (Figure 17), the drought occurrences in the future are observed to be less frequent and more steady, although the instances of drought post-2030 are observed to be a lot less under the SSP5-8.5 scenario. The climate of KSB is also humid, which indicates a similar future drought situation as that of $\mathrm{BK}$. While $\mathrm{AV}$ is already a dry region, $\mathrm{BK}$ and $\mathrm{KSB}$, which are humid regions, are expected to have higher projected precipitation in the near future. This corroborates the statement by Salvi et al. [72] that wet areas are getting wetter and dry areas are getting drier.

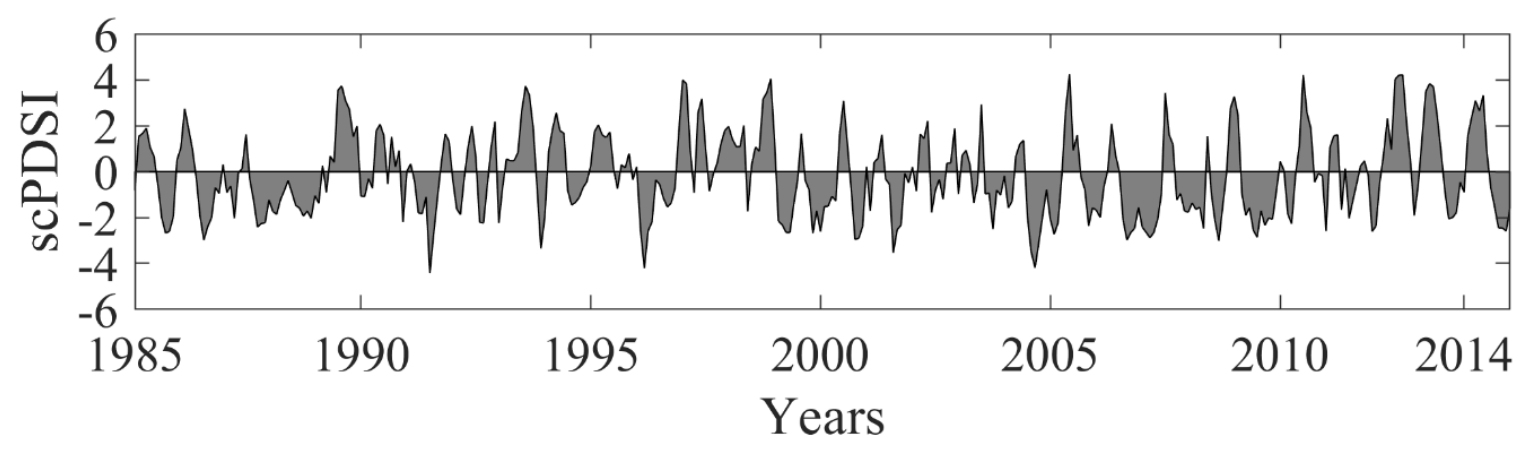

Figure 15. Grid-averaged scPDSI values from 1985 to 2014 for study area BK based on historic observed data.
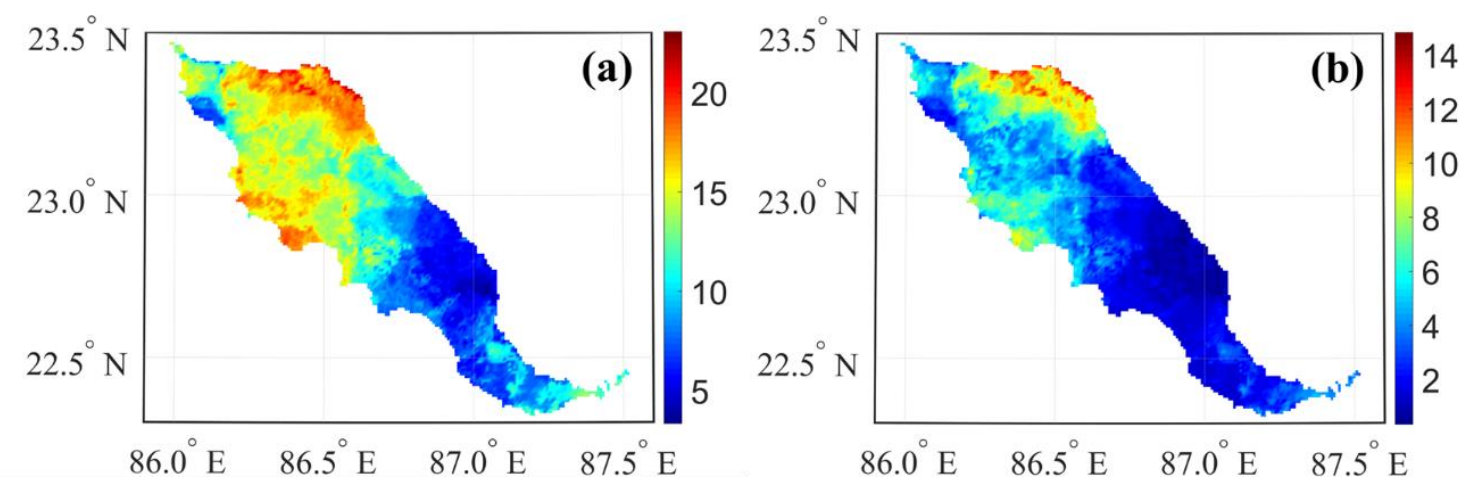

Figure 16. Drought duration maps for historic observed data for study area KSB. (a) For severe drought and (b) for extreme drought. The scale bar represents months of drought in historic 30 years (1985-2014).

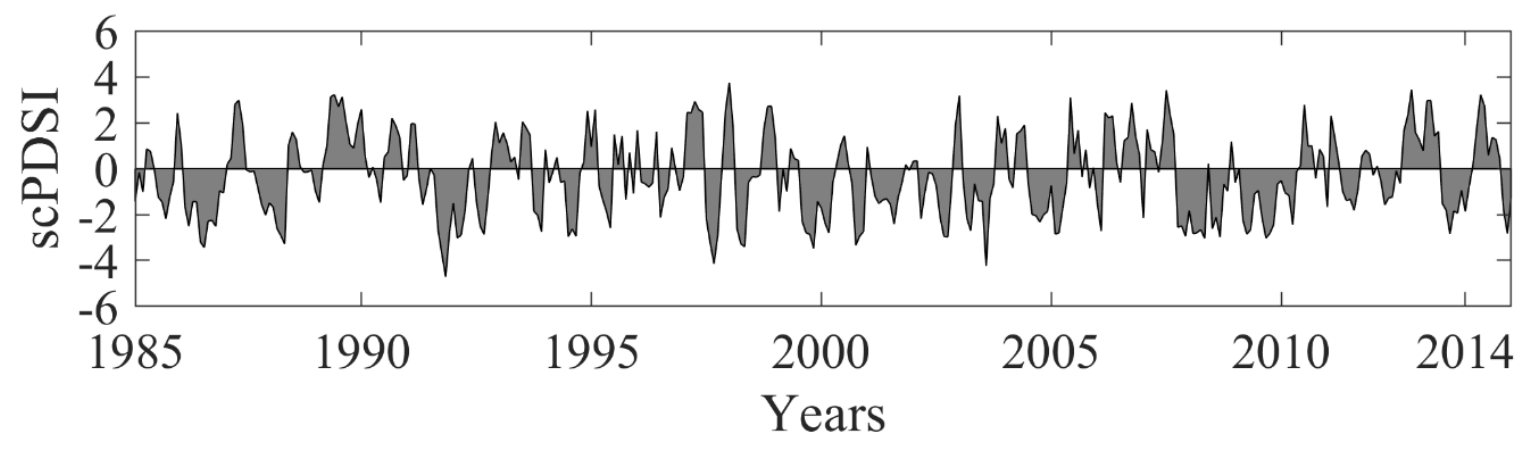

Figure 17. Grid-averaged scPDSI values from 1985 to 2014 for study area KSB based on historic observed data.

On the basis of previous accounts of drought durations in each study area, a fair sense of drought duration that is normally experienced can be established. Based on Bhuiyan et al. [61], in the AV, the severe to extreme drought occurred during 1984-1987. Then, again in the year 2000, the majority of the region faced severe to extreme drought. Based on this, the length of severe to extreme drought 
experienced is roughly around 36-48 months. Hence, for the near future, less than 10 months of extreme drought as per all the scenarios seems less harmful. Since drought studies have not been separately carried out for a long period in the respective study area, an older account of drought had to be referred to. Similarly, Thomas et al. [62] for the BK region stated that most of the districts in the region have been facing severe to extreme droughts for 3-5 months between the time period of 1976-2009. As per the current study as well, the extreme droughts are expected to last at most 5-10 months based on results under all the scenarios in the near future. Likewise, AK Mishra and Desai [63] reported that short term droughts in KSB lasted for 1.5-2 months. Medium-term droughts lasted for 3-5 months. Long terms droughts lasted for 10 to 22 months. The severity of the droughts was not taken in the account by the study, but the length of drought in the study area gives an idea that extreme drought may not have bigger implications. It is noteworthy that the duration of extreme droughts in all of the study areas under the SSP5-8.5 scenario is less compared to extreme droughts under SSP1-2.6 and SSP2-4.5 scenarios. In all of the three study areas, the duration of extreme droughts has not been observed to be significant. Therefore, the projected duration of extreme droughts during the near future does not seem to pose greater setbacks.

Based on the results, all the regions may experience severe droughts in the near future. Hence, droughts may affect the living conditions in these regions. The results also provide insights into water resources management in India. Soil moisture deficit can be a concerning problem due to the longer drought period in these regions. Hydrologic processes, such as runoff and water storage, can be disrupted due to a lack of soil moisture. Subsequently, due to lack of soil moisture, agriculture output may be affected. Half of the Indian population is based on the agricultural economy. From 1983 to 2014, the contribution of agriculture to gross domestic product (GDP) of India has plummeted significantly by $25 \%$ [73]. This drop in agricultural GDP has contributed to agronomic inefficiency, leading to a concerning risk to food security in the future. India as a whole is projected to have a population of 1.8 billion at the end of 2050, according to the United Nations [74]. A majority of cities are located in BK and KSB and contains major Indian rivers. The current study indicates severe droughts in all the study areas and especially in BK and KSB, which, in turn, will affect water availability. This will seriously impact the presence of plant species, resulting in desertification. The projection of electricity demand shows an increasing rate in the future. Due to projected drought situations, the dependable hydroelectric power generation can be at stake due to reduced water availability. This can create a shortage of power in the future, leading to greater economic setbacks. Therefore, suitable preparedness is required, taking into consideration the results of the current study, to lessen the risk posed by drought in these respective regions in the future. The plans and policies should be placed while also considering the regional implications of the projected hazard.

\section{Conclusions}

This study uses the latest CMIP6 to forecast and quantify the future droughts in various regions of India. A high-resolution drought data was generated, considering simulated precipitation and temperature data as a basis, for a drought index commonly known as scPDSI. The study used historical modeled precipitation and temperature from CMIP6 and historically observed precipitation and temperature data to bias-correct the future CMIP6 data. The future droughts were quantified for different emissions, land-use, and societal constraints, commonly called scenarios. The findings of this research are noted down as follows:

(1) Prolonged durations of severe drought (scPDSI $\leq-3$ ) can be expected under the SSP2-4.5 and SSP 5-8.5 scenarios between 2015 and 2044.

(2) The period of a possible lengthy spell of worse drought situation can be identified as the period between the mid-2030s and early 2040s for the Araveli and Bundelkhand regions.

(3) Distinct drought durations, even in the smallest of the vulnerable areas, were identified due to fine spatial resolution of the obtained drought index dataset. 
The MME mean of seven different GCMs was created to address the variability among climate models, and model-induced uncertainties were able to accumulate the overall effects giving equal weightage to all models. A succession of dry and wet periods observed in thirty years of the future shows the effectiveness of the MME mean. The outcome of this study shows that the occurrence of drought exists nearly every decade in warming climate under all scenarios. Particularly, drought durations in the AV region around the 2030s can be a noteworthy situation in the future because two of the scenarios show the possibility of such drought. A severe drought of around 21 months in total in the near future can be expected under the worst of the scenarios. Continuous drought in a place like $\mathrm{AV}$, which is known for its arid climate mostly throughout the year, can be concerning. Hence, proper management of water resources should be planned in the future, mostly in the eastern and western regions of AV. For BK, dry periods are dominant in the future with shorter durations of wet periods appearing, intermittently raising concerns in all scenarios except for SSP2-4.5. However, a total of 2-3 years of severe drought in the near future can be expected under the projection of the SSP5-8.5 scenario. Unlike in AV and BK, KSB can be expected to face serious droughts in the 2020s. A total of around 35 months of extreme drought can be expected under the SSP2-4.5 scenario. It can be concluded that worse climatic situations may somewhat lead to favorable conditions for inducing droughts. However, significant differences between climate scenarios of CMIP6 in detecting future droughts were not noticed. The future changes in climate tend to show that severe drought durations will most probably be a concern as per the analysis under SSP2-4.5 and SSP5-8.5 scenarios for all study areas. The mid-2030s can be considered as drought-prone periods regardless of severity in climatic situations. The drought occurrences, durations, and intensity may probably decrease after the late years of the 2030s.

The study areas considered for this research work have been traditionally drought-prone. With the development of a high-resolution drought index spanning a future period of thirty years, remote and less developed localities or districts can benefit from timely solutions of water management as a result of future drought forecasting. Timely water management done as a result of forecasting can have positive benefits in food security, agricultural practices, health, and the economy of any given place. Hence, this study can be applied to forecast drought in other smaller regions while taking advantage of finer spatial resolution.

Author Contributions: Conceptualization, A.K.; formal analysis, A.S. and M.M.R.; investigation, A.S. and M.M.R.; software, A.S., M.M.R., and R.J.; supervision, A.K. and P.M.; writing-original draft, A.S. and A.K.; writing-review and editing, A.S., M.M.R., A.K., R.J., and P.M. All authors have read and agreed to the published version of the manuscript.

Funding: This research received no external funding.

Acknowledgments: The authors would like to thank the editor and four anonymous reviewers for constructive feedback. We acknowledge the modeling groups, the Program for Climate Model Diagnosis and Intercomparison, and the World Climate Research Programme (WCRP) Working Group on Coupled Modelling for their roles in making available the WCRP Coupled Model Intercomparison Project phase 6 (CMIP6) multimodel datasets. The authors would like to express their appreciation for the support provided by the Office of the Vice-Chancellor for Research at Southern Illinois University, Carbondale. The current study was carried out using various publicly available datasets.

Conflicts of Interest: No potential conflict of interest was reported by the authors.

\section{References}

1. AghaKouchak, A.; Nakhjiri, N. A near real-time satellite-based global drought climate data record. Environ. Res. Lett. 2012, 7, 044037. [CrossRef]

2. Venkataraman, K.; Tummuri, S.; Medina, A.; Perry, J. 21st century drought outlook for major climate divisions of Texas based on CMIP5 multimodel ensemble: Implications for water resource management. J. Hydrol. 2016, 534, 300-316. [CrossRef]

3. Rahaman, M.M.; Thakur, B.; Kalra, A.; Ahmad, S. Modeling of GRACE-derived groundwater information in the Colorado River Basin. Hydrology 2019, 6, 19. [CrossRef] 
4. Brown, C.; Meeks, R.; Hunu, K.; Yu, W. Hydro climatic risk to economic growth in sub-Saharan Africa. Clim. Chang. 2011, 106, 621-647. [CrossRef]

5. Hartmann, D.L.; Tank, A.M.G.K.; Rusticucci, M. Climatic Change 2013: The Physical Science Basis; IPCC Fifth Assessment Report; IPCC: Geneva, Switzerland, 2013; pp. 31-39.

6. Trenberth, K.E.; Dai, A.; Van Der Schrier, G.; Jones, P.D.; Barichivich, J.; Briffa, K.R.; Sheffield, J. Global warming and changes in drought. Nat. Clim. Chang. 2014, 4, 17-22. [CrossRef]

7. Dai, A. Increasing drought under global warming in observations and models. Nat. Clim. Chang. 2013, 3, 52-58. [CrossRef]

8. Peterson, T.C.; Heim, R.R., Jr.; Hirsch, R.; Kaiser, D.P.; Brooks, H.; Diffenbaugh, N.S.; Dole, R.M.; Giovannettone, J.P.; Guirguis, K.; Karl, T.R.; et al. Monitoring and understanding changes in heat waves, cold waves, floods, and droughts in the United States: State of knowledge. Bull. Am. Meteorol. Soc. 2013, 94, 821-834. [CrossRef]

9. Masih, I.; Maskey, S.; Mussá, F.E.; Trambauer, P. A review of droughts on the African continent: A geospatial and long-term perspective. Hydrol. Earth Syst. Sci. 2014, 18, 3635. [CrossRef]

10. Spinoni, J.; Vogt, J.; Naumann, G.; Carrao, H.; Barbosa, P. Towards identifying areas at climatological risk of desertification using the Köppen-Geiger classification and FAO aridity index. Int. J. Climatol. 2015, 35, 2210-2222. [CrossRef]

11. Kumar, K.R.; Sahai, A.K.; Kumar, K.K.; Patwardhan, S.K.; Mishra, P.K.; Revadekar, J.V.; Kamala, K.; Pant, G.B. High-resolution climate change scenarios for India for the 21st century. Curr. Sci. 2006, 90, 334-345. [CrossRef]

12. Shackley, S.; Deanwood, R. Stakeholder Perceptions of Climate Change Impacts at the Regional Scale: Implications for the Effectiveness of Regional and Local Responses. J. Environ. Plan. Manag. 2002, 45, 381-402. [CrossRef]

13. Zhao, T.; Dai, A. Uncertainties in historical changes and future projections of drought. Part II: Model-simulated historical and future drought changes. Clim. Chang. 2016, 144, 535-548. [CrossRef]

14. Ault, T.R.; Cole, J.E.; Overpeck, J.T.; Pederson, G.T.; Meko, D.M. Assessing the risk of persistent drought using climate model simulations and paleoclimate data. J. Clim. 2014, 27, 7529-7549. [CrossRef]

15. Cook, B.I.; Smerdon, J.E.; Seager, R.; Coats, S. Global warming and 21 st century drying. Clim. Dyn. 2014, 43, 2607-2627. [CrossRef]

16. Zhao, T.; Dai, A. The magnitude and causes of global drought changes in the twenty-first century under a low-moderate emissions scenario. J. Clim. 2015, 28, 4490-4512. [CrossRef]

17. Meehl, G.A.; Stocker, T.F.; Collins, W.D.; Friedlingstein, P.I.E.R.R.E.; Gaye, A.T.; Gregory, J.M.; Kitoh, A.K.I.O.; Knutti, R.E.T.O.; Murphy, J.M.; Noda, A.K.I.R.A.; et al. Global climate projections. Climate change 2007: The physical science basis. In Contribution of Working Group I to the Fourth Assessment Report of the Intergovernmental Panel on Climate Change; Cambridge University Press: Cambridge, UK, 2007; pp. 747-845.

18. Touma, D.; Ashfaq, M.; Nayak, M.A.; Kao, S.C.; Diffenbaugh, N.S. A multi-model and multi-index evaluation of drought characteristics in the 21st century. J. Hydrol. 2015, 526, 196-207. [CrossRef]

19. Marengo, J.A.; Torres, R.R.; Alves, L.M. Drought in Northeast Brazil-Past, present, and future. Theor. Appl. Climatol. 2017, 129, 1189-1200. [CrossRef]

20. Kunkel, K.E.; Liang, X.Z.; Zhu, J.; Lin, Y. Can CGCMs simulate the twentieth-century "warming hole" in the central United States? J. Clim. 2006, 19, 4137-4153. [CrossRef]

21. Pathak, R.; Sahany, S.; Mishra, S.K.; Dash, S.K. Precipitation Biases in CMIP5 Models over the South Asian Region. Sci. Rep. 2019, 9, 9589. [CrossRef]

22. Solomon, S.; Manning, M.; Marquis, M.; Qin, D. Climate Change 2007-the Physical Science Basis: Working Group I Contribution to the Fourth Assessment Report of the IPCC; Cambridge University Press: Cambridge, UK, 2007; p. 4.

23. Wood, A.W.; Leung, L.R.; Sridhar, V.; Lettenmaier, D.P. Hydrologic implications of dynamical and statistical approaches to downscaling climate model outputs. Clim. Chang. 2004, 62, 189-216. [CrossRef]

24. Fowler, H.J.; Kilsby, C.G. Using regional climate model data to simulate historical and future river flows in northwest England. Clim. Chang. 2007, 80, 337-367. [CrossRef]

25. Hay, L.E.; Wilby, R.L.; Leavesley, G.H. A comparison of delta change and downscaled GCM scenarios for three mountainous basins in the United States 1. JAWRA 2000, 36, 387-397. [CrossRef]

26. Nath, R.; Nath, D.; Li, Q.; Chen, W.; Cui, X. Impact of drought on agriculture in the Indo-Gangetic Plain, India. Adv. Atmos. Sci. 2017, 34, 335-346. [CrossRef] 
27. Sharma, S.; Mujumdar, P. Increasing frequency and spatial extent of concurrent meteorological droughts and heatwaves in India. Sci. Rep. 2017, 7, 1-9. [CrossRef] [PubMed]

28. Zhang, X.; Obringer, R.; Wei, C.; Chen, N.; Niyogi, D. Droughts in India from 1981 to 2013 and Implications to Wheat Production. Sci. Rep. 2017, 7, 44552. [CrossRef]

29. AghaKouchak, A.; Feldman, D.; Hoerling, M.; Huxman, T.; Lund, J. Water and climate: Recognize anthropogenic drought. Nature 2015, 524, 409-411. [CrossRef]

30. Zhao, M.; Running, S.W. Drought-induced reduction in global terrestrial net primary production from 2000 through 2009. Science 2010, 329, 940-943. [CrossRef]

31. Arya, A.S.; Dhinwa, P.S.; Pathan, S.K.; Raj, K.G. Desertification/land degradation status mapping of India. Curr. Sci. 2009, 97, 1478-1483.

32. Bhalme, H.N.; Mooley, D.A. Large-scale droughts/floods and monsoon circulation. Mon. Weather Rev. 1980, 108, 1197-1211. [CrossRef]

33. De, U.S.; Dube, R.K.; Rao, G.P. Extreme weather events over India in the last 100 years. J. Ind. Geophys. Union 2005, 9, 173-187.

34. Khanal, A.R.; Mishra, A.K. Enhancing food security: Food crop portfolio choice in response to climatic risk in India. Glob. Food Secur. 2017, 12, 22-30. [CrossRef]

35. Lau, W.K.; Waliser, D.E. Intraseasonal Variability in the Atmosphere-Ocean Climate System; Springer Science \& Business Media: Berlin/Heidelberg, Germany, 2011. [CrossRef]

36. Kitoh, A.; Endo, H.; Krishna Kumar, K.; Cavalcanti, I.F.; Goswami, P.; Zhou, T. Monsoons in a changing world: A regional perspective in a global context. J. Geophys. Res. Solid Earth Atmos. 2013, 118, 3053-3065. [CrossRef]

37. Birkenholtz, T. Knowing climate change: Local social institutions and adaptation in Indian groundwater irrigation. Prof. Geogr. 2014, 66, 354-362. [CrossRef]

38. Sharmila, S.; Joseph, S.; Sahai, A.K.; Abhilash, S.; Chattopadhyay, R. Future projection of Indian summer monsoon variability under climate change scenario: An assessment from CMIP5 climate models. Glob. Planet. Chang. 2015, 124, 62-78. [CrossRef]

39. Sarthi, P.P.; Ghosh, S.; Kumar, P. Possible future projection of Indian Summer Monsoon Rainfall (ISMR) with the evaluation of model performance in Coupled Model Inter-comparison Project Phase 5 (CMIP5). Glob. Planet. Chang. 2015, 129, 92-106. [CrossRef]

40. Stocker, T.F.; Dahe, Q.; Plattner, G.K.; Alexander, L.V.; Allen, S.K.; Bindoff, N.L.; Xie, S.P. Technical summary. Climate Change 2013: The Physical Science Basis. In Contribution of Working Group I to the Fifth Assessment Report of the Intergovernmental Panel on Climate Change; Cambridge University Press: Cambridge, UK, 2013; pp. 33-115. [CrossRef]

41. TERI (The Energy Research Institute). Assessing Climate Change Vulnerability and Adaptation Strategies for Maharashtra: Maharashtra State Adaptation Action Plan on Climate Change (MSAAPC); The Energy and Resources Institute: New Delhi, India, 2014.

42. Mishra, V.; Shah, R.; Thrasher, B. Soil moisture droughts under the retrospective and projected climate in India. J. Hydrometeorol. 2014, 15, 2267-2292. [CrossRef]

43. Mallya, G.; Mishra, V.; Niyogi, D.; Tripathi, S.; Govindaraju, R.S. Trends and variability of droughts over the Indian monsoon region. Weather Clim. Extrem. 2016, 12, 43-68. [CrossRef]

44. Thomas, J.; Prasannakumar, V. Temporal analysis of rainfall (1871-2012) and drought characteristics over a tropical monsoon-dominated State (Kerala) of India. J. Hydrol. 2016, 534, 266-280. [CrossRef]

45. Naresh Kumar, M.; Murthy, C.S.; Sesha Sai, M.V.; Roy, P.S. Spatiotemporal analysis of meteorological drought variability in the Indian region using standardized precipitation index. Meteorol. Appl. 2012, 19, 256-264. [CrossRef]

46. Ojha, R.; Nagesh Kumar, D.; Sharma, A.; Mehrotra, R. Assessing severe drought and wet events over India in a future climate using a nested bias-correction approach. J. Hydrol. Eng. 2013, 18, 760-772. [CrossRef]

47. Liu, B.; Asseng, S.; Müller, C.; Ewert, F.; Elliott, J.; Lobell, D.B.; Martre, P.; Ruane, A.C.; Wallach, D.; Jones, J.W.; et al. Similar estimates of temperature impacts on global wheat yield by three independent methods. Nat. Clim. 2016, 6, 1130-1136. [CrossRef]

48. Vicente-Serrano, S.M.; Beguería, S.; López-Moreno, J.I. A multiscalar drought index sensitive to global warming: The standardized precipitation evapotranspiration index. J. Clim. 2010, 23, 1696-1718. [CrossRef] 
49. Li, H.; Sheffield, J.; Wood, E.F. Bias correction of monthly precipitation and temperature fields from Intergovernmental Panel on Climate Change AR4 models using equidistant quantile matching. J. Geophys. Res. 2010, 115, D10101. [CrossRef]

50. O'Neill, B.C.; Tebaldi, C.; van Vuuren, D.P.; Eyring, V.; Friedlingstein, P.; Hurtt, G.; Knutti, R.; Kriegler, E.; Lamarque, J.-F.; Lowe, J.; et al. The Scenario Model Intercomparison Project (ScenarioMIP) for CMIP6. Geosci. Model Dev. 2016, 9, 3461-3482. [CrossRef]

51. Leander, R.; Buishand, T.A. Resampling of regional climate model output for the simulation of extreme river flows. J. Hydrol. 2007, 332, 487-496. [CrossRef]

52. Panofsky, H.A.; Brier, G.W. Some Applications of Statistics to Meteorology; Pennsylvania State University, University Park: State College, PA, USA, 1968; p. 224.

53. Herrera, D.; Ault, T. Insights from a new high-resolution drought atlas for the Caribbean spanning 1950-2016. J. Clim. 2017, 30, 7801-7825. [CrossRef]

54. van der Schrier, G.; Jones, P.D.; Briffa, K.R. The sensitivity of the PDSI to the Thornthwaite and Penman-Monteith parameterizations for potential evapotranspiration. J. Geophys. Res. 2011, 116, D03106. [CrossRef]

55. Lockwood, J.G. Is potential evapotranspiration and its relationship with actual evapotranspiration sensitive to elevated atmospheric CO2 levels? Clim. Chang. 1999, 41, 193-212. [CrossRef]

56. Allen, R.G.; Smith, M.; Perrier, A.; Pereira, L.S. An update for the definition of reference evapotranspiration. ICID Bull. 1994, 43, 1-34. [CrossRef]

57. Allen, R.G. An update for the calculation of reference evapotranspiration. ICID Bull. 1994, 43, 35-92.

58. Allen, R.G.; Pereira, L.S.; Raes, D.; Smith, M. Crop Evapotranspiration-Guidelines for Computing Crop Water Requirement; FAO Irrigation and drainage paper 56; FAO: Rome, Italy, 1998; Voluem 300, p. D05109.

59. Alley, W.M. The Palmer drought severity index: Limitations and assumptions. J. Appl. Meteorol. Climatol. 1984, 23, 1100-1109. [CrossRef]

60. Wells, N.; Goddard, S.; Hayes, M.J. A self-calibrating Palmer drought severity index. J. Clim. 2004, 17, $2335-2351$. [CrossRef]

61. Bhuiyan, C.; Singh, R.P.; Kogan, F.N. Monitoring drought dynamics in the Aravalli region (India) using different indices based on ground and remote sensing data. Int. J Appl. Earth Obs. 2006, 8, 289-302. [CrossRef]

62. Thomas, T.; Nayak, P.C.; Ghosh, N.C. Spatiotemporal analysis of drought characteristics in the bundelkhand region of central india using the standardized precipitation index. J. Hydrol. Eng. 2015, 20, 05015004. [CrossRef]

63. Mishra, A.K.; Desai, V.R. Spatial and temporal drought analysis in the Kansabati river basin, India. Int. J. River Basin Manag. 2005, 3, 31-41. [CrossRef]

64. Weigel, A.P.; Liniger, M.A.; Appenzeller, C. Can multi-model combination really enhance the prediction skill of probabilistic ensemble forecasts? J. Atmos. Sci. 2008, 134, 241-260. [CrossRef]

65. Pierce, D.W.; Barnett, T.P.; Santer, B.D.; Gleckler, P.J. Selecting global climate models for regional climate change studies. Proc. Natl. Acad. Sci. USA 2009, 106, 8441-8446. [CrossRef]

66. Warner, T.T. Numerical Weather and Climate Prediction; Cambridge University Press: Cambridge, UK, 2010.

67. Gupta, V.; Kumar Jain, M.; Singh, V.P. Multivariate modeling of projected drought frequency and hazard over India. J. Hydrol. Eng. 2020, 25, 04020003. [CrossRef]

68. Bisht, D.S.; Sridhar, V.; Mishra, A.; Chatterjee, C.; Raghuwanshi, N.S. Drought characterization over India under projected climate scenario. Int. J. Climatol. 2019, 39, 1889-1911. [CrossRef]

69. Bollasina, M.A.; Ming, Y.; Ramaswamy, V. Anthropogenic aerosols and the weakening of the South Asian summer monsoon. Science 2011, 334, 502-505. [CrossRef] [PubMed]

70. Mishra, V.; Somalik, B.V.; Lettenmaier, D.P.; Wallace, J.M. A prominent pattern of year-to-year variability in Indian summer monsoon rainfall. Proc. Natl. Acad. Sci. USA 2012, 109, 7213-7217. [CrossRef] [PubMed]

71. Gupta, V.; Jain, M.K. Investigation of multi-model spatiotemporal mesoscale drought projections over India under climate change scenario. J. Hydrol. 2018, 567, 489-509. [CrossRef]

72. Salvi, K.; Ghosh, S. High-resolution multisite daily rainfall projections in India with statistical downscaling for climate change impacts assessment. J. Geophys. Res. 2013, 118, 3557-3578. [CrossRef] 
73. Ministry of Agriculture and Farmers' Welfare. State of Indian Agriculture 2015-16; Ministry of Agriculture and Farmers' Welfare: New Delhi, India, 2016.

74. United Nations. World Population Prospects 2019. Volume I: Comprehensive Tables; United Nations: New York, NY, USA, 2019.

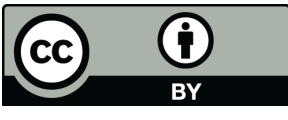

(C) 2020 by the authors. Licensee MDPI, Basel, Switzerland. This article is an open access article distributed under the terms and conditions of the Creative Commons Attribution (CC BY) license (http://creativecommons.org/licenses/by/4.0/). 